\title{
JUSTINO FERNANDEZ
}

\section{A T A L OGO \\ DE LAS EXPOSICIONES DE ARTE \\ EN 1952}

SUPLFMENTO DEL NUM. 21 DE LOS ANALES DEL INSTITUTO DE INVESTIGACIONES ESTETICAS

M E X I C O

$\begin{array}{llll}1 & 9 & 5 & 3\end{array}$ 
DOI: http://dx.doi.org/10.22201/iie.18703062e.1953.sup1.2455 
El año de 1952 marca una cumbre en las exposiciones de artc mexicano por la extraordinaria que, organizada por el Instituto Nacional de Bellas Artes, fue presentada en el Museo de Arte Moderno de París y después en Estocolmo y en Londres. Un fantástico acervo de arte indígena antiguo, arte colonial, arte moderno y contemporáneo, más una gran sección dedicada al arte popular, componía el conjunto, cubriendo todos los aspectos de nuestro arte. En la ocasión en que fue presentada en París, escribí unos artículos 1 que espero hayan dado alguna idea del acontecimiento. Porque ni unás ni menos de eso se trata, de un acontecimiento para Europa y para México, puesto que por primera vez hemos tenido la oportunidad de presentar - y los europeos de contemplar- una de las más formidables exposiciones de todos los tiempos. Colaboraron en dicha exposición el Instituto Nacional de Antropología e Historia y el Instituto Nacional Indigenista, así como instituciones extranjeras y particulares que enriquecieron el acervo prestando obras de sus colecciones.

No es posible iucluir aquí el catálogo completo de la exposición que ha constituído un sonado buen éxito internacional, más, puede asegurarse que la selección de obras, en general, fué excelente y que el entonces subdirector del Instituto $\mathrm{Na}$ cional de Bellas Artes, Fernando Gamboa, así como todos sus colaboradores, merece todo género de felicitaciones por el esfuerzo realizado, por la responsabilidad asumida, por su capacidad como museógrafo y por el buen éxito a que supo llevarlo todo en cada una de las grandes ciudades en que fue presentada la exposición. Es de justicia, me parece, reconocer lo anterior.

Aquí sólo se trata de recordar el evento para que quede registrado en estos catálogos anuales. ${ }^{2}$ De su significación y provecho habría que ocuparse más cxtensamente en otro sitio.

No obstante la empresa que fué organizar la exposición anterior el Instituto Nacional de Bellas Artes presentó en México una serie de exposiciones, a saber: en el Palacio de Bellas Artes las de Ceferino Colinas (escultura), Clara Porset (El Arte en la Vida Diaria), "Arquitectura Popular Mexicana", Richard A. Florsleeim (litografías), "Grabados Mexicanos Contemporáneos" Leonardo da Vinci

1 "El Universal", mayo 19, junio 2 y 12, 1952.

2 Una información completa sobre esta exposición viajera requeriría un volumen que es de desearse se publique en el futuro. En cada una de las ciudades en que se presentó se editaron catálogos en los idiomas correspondientes. 
(organizada por la UNESCO), "Grabados interpretando el programa de la Secretaría de Recursos Hidráulicos" for el Frente Nacional de Artes Plásticas; Jesús Guerrero Galván; en la "Galería Josế Clemente Orozco" se exhibicron "Los Caprichos" de Goya y se presentó una exposición del Tnstituto Nacional de la Juventud Mexicana; en la "Galería José Giladalupe Posada" se expnsso una colección de grabados y litografías sobre Emiliano Zapata, perteneciente al Dr. Alvar Carrillo Gil; en la "Galería Cervantes" se presentí una exposición de la "Escuela de Pintura y Escultura de Chiapas" establecida en Tuxtla Gutiérrez; en la "Galería de Ventas Libres" se vieron las siguientes exposiciones: Amador J I11go, Celia Calclerón, Iosé Gutiérrez, Ignacio Aguirre, Nicolás Moreno, Gustavo Montoya y dos colectivas.

El Instituto Nacional de Antronología presentó una exposición de Cultura Egipcia y otra con el material proveniente del descubrimiento de la cámara subterránea de Palenque; y el Museo de Artes c Indrstrias Populares, dependiente (le) Instituto exhibió trabajos de platería y otros en relación con "Posadas, Navidad y Reyes".

Los Institutos extranjeros de Relaciones Culturales también estuvieron activos, en el Mexicano-Norteamericano tuvieron lugar las siguientes exposiciones: Martha Watson Sauer, Edwin Boyd Johnson (fotografías), Lester Epstein, Emile Roure, Howard Smith, Raymond Toloczko, Thea Ranısy y Clarise Lindahl Hopps; en el Anglo-Mexicano: Parboo Singl, Celia Calderón, Toby Joysmith, Manuel Alvarez Bravo (fotografías), Allan Cash (fotografías) y Valetta Swann.

Como anualmente acostumbra el diario "Excelsior", organizó la "Ficsta de la Flor" en el mes de mayo y en los pabellones que existen para este objeto en el Bosque de Chapultepec; también presentó el mismo diario, en su edificio, la exposición del artista boliviano Guillermo Heguigorri.

Las galerías de arte de la ciudad de México presentaron numerosas exposiciones de artistas mexicanos y extranjeros, como sigue:

Galería de Arte Mexicano: José Feher, Charles Michel, Raúl Anguiano, Mathias Goeritz, Angelina Beloff, Micliael Baxter, Enrique Climent y Ricardo Martínez.

Galeria de Arte Moderno: Elaine Hamilton O'Neal, Fernando Marcos y Osvaldo Reyes, Andrés Salgo, José Julis Aguerrebere, Suzanne Daco de Genachte (grabados de Bélgica), Mariano Paredes, Jesús Ortiz Tajonar, Clea Gaston (serigrafías), Pintores de la Escuela de París (L'Art Pictural de Paris), Martha Adams, Carlos R. López, Exposición Colectiva de Pintura Mexicana, Exposición de Grabados de escuela francesa, Geles Cabrera (escultura), Antonio Magdaleno, Exposición de remate por cambio de local.

Galería de Arte Contemporánco: Reno Ferrugio; José Clemente Orozeo; "De Carnavales a Judas en la Pintura Mexicana" del diario "Novedades" y el suplemento "México en la Cultura"; Macías Báez (dibujos para el vestuario del Ballet Bonampak); Emma Reyes; Antonio Peláez; Exposición colectiva de fin de año.

Galeria Reger: Pintura de Haití.

Galería Prisse: Héctor Xavier, Vlady, Bartoli. 
Galería Decor, S. A.: Antonio Rodríguez Luna.

Galería de Arte de la "Libreria Juárez": Ramón Alva de la Canal, Armando García Núñez, J. Cañas (animales).

Otras instituciones o grupos que instalaron exposiciones son las siguientes:

Mexico City College : 4a. Exposición anual de los estudiantes de Arte.

Escuela de Pintura y Escultura de Esmeralda y Anexo de Coyoacán, de la Secretaria de Educación Pública; Exposición de obras de Veteranos de la Guerra en la "Biblioteca Cervantes".

Universidad Femenina: Exposición de trabajos de las alumnas del curso do Decoración.

Escuela de Artes del Libro, de la Secretarín de Educación Pública. Exposición de trabajos de los estudiantes.

Ateneo Español de Mćxico: Xavier de Oteyza.

Aliansa Francesa: Luis Abad Carretero.

Grupo Estudio Bernal: Exposición de trabajos de arte publicitario.

Sociedad de Grabadores: Exposición en Homenaje a Posada; en Guadalajara: Exposición de Grabados a Color en la Galería de Arte Moderno.

Centro de Arte Mexicano Contemporáneo: en Toluca, Exposición de la Estampa Cubana, en el Museo de Bellas Artes; en México, Exposición Colectiva de Estampas a color y la de Erasto Cortés Juárez.

Pabcllón de la Flor, en Chapultepec: 1a. Exposición arual de artistas mexicinnos y españoles residentes en México.

La Peña de Amigos del Arte, en Puebla, Pue.: Homenaje a Posada. Tres exposiciones de Desiderio Hernández Xochitiotzin.

Unión de Artes Plásticas, en Puebla, Pue.: Ednardo Hernández Xochitiotzin.

Galcrías Artísticas, en Monterrey, N. L.: Exposición de José Guadalupe Ramírez, presentada por el Departamento de Acción Social de la Universidad de Nuevo León.

Por último, el General Igrnicio M. Beteta expuso sus obras de pintura en la Galería del Hotel del Prado; y Francisco González exhibió sus pinturas en una casa particular de Coyoacán, D. F.

Tal es el panorama de las actividades artísticas de México en materia cle exposiciones. Debe mencionarse, a lo menos, las obras que se realizan en la Ciudaul Universitaria, murales, casi todis en mosaicos: Diego Rivera en el Estadio; David 
DOI: http://dx.doi.org/10.22201/iie.18703062e.1953.sup1.2455

Alfaro Siqueiros en el edificio de la Rectoría; Juan O'Gorman en la Biblioteca; José Chávez Morado en uno de los edificios de Ciencias. Por otra parte, Rufino Tamayo terminó los dos excelentes murales que le encomendó el Instituto Nacional de Bellas Artes, en el Palacio de Bellas Artes.

JUSTINO FERnÁNDEZ 


\section{CATALOGO DE LAS EXPOSICIONES DE ARTE EN 1952}

\section{ENERO}

* Guillermo Heguigorri-Exposición de pintura y tallado presentada por la Embajada de Bolivia y el diario "Excelsior", en el salón de exposiciones "Excelsior", Paseo de la Reforma, 16. Desde el 15 de enero.

\section{Estilo Ckrakcle:}

1. Adoración de los Reyes.-2. S. Corazún de Jesús.-3. La Virgen y el Niño-4. La Cena.-5. Virgen de Guadalupe.-6. La Cruxificción-7. Penitente.-8. Ermitaño.-9. Estudio de dorso-10. Festín.-11. Composición.-12. Música.-13. Figura.-14. Médico de pueblo-15. Dentista.-16. Autorretrato.-17. San Francisco.-18. Motivo Boliviano.-19. Estudio-20. Estudio.

Ojeos:

1. Estilización (motivo boliviano).-2. Cigarro.-3. Mujer-4. Calle Sagárnaga5. Calle Linares.-6. Danza de los diablos.-7. Tono azul.-8. Llama.-9. Movimiento--10. Noche.-11. Reflejo.-12. Motivo local.-13. Calle local.-14. San Juan-15. Estudio.

Tallas en madera:

1. Cabeza de indígena.-2. Cabeza de viejo-3. Cabeza de mujer y 30 acuarelas con motivos distintos.

* Grupo Estudio Bernal-Exposición de los trabajos ejecutados durante el año de 1951, sobre Arte Publicitario y Dibujo Artístico, presentada en su local de Héroes, 18-3, Colonia Guerrero. Del 15 de enero al 15 de febrero.

* Remo Ferrugion-Exposición de pintura jresentada por la Galería de Arte Contemporáneo, Amberes, 12. Desde el 15 de enero. 
1. La Luna y el Magucy.-2. Jacarauda-3. La Luna y la Playa.-4. Naturaleza muerta No. 1.-5. Naturaleza muerta No. 2,-6. Naturaleza muerta No. 3.7. Serranía-8. Camino a Oaxaca-9. Nostalgia-10. La Danza-11. Acapulco.-12. Zócalo.-13. Cuernawaca.-14. Madre e Hijo.-15. La Mujer del pelo rojo.

* Anador Lugo.-Exposición de pintura presentada por el Salón de la Pláslica Mexicana, Galería de Ventas Libres, del Instituto Nacional de Bellas Artes. Del 17 de enero al 14 de febrero.

Oleus, 1951 :

1. Impresicin del Canal de Churubusco.-2. Ta Calzada-3. La Casa roja--4. Comienza la tormenta. Col. Sr. Fcliciano Peña--5. Cabeza-6. Preparando la tierra--7. Objetos sobre la terraza.-8. Al final de la cosecla.-0. Al taño de la Concordia.-10. Las Minas de Santiaguito.-11. Incendio en la Colonia de los Doctores.-12. Por el Canal de Churubusco.-13. Inpresión de la Playa de El Revolcadero.-14. Las Minas de Tezontle de Acallualtepec--15. E1 Lago de Texcoco desde las Minas de Tezontle.-16. La Mina de Tezontle.17. En el baño de la amistad, de la amistad...

Gounches, 1951:

18. Granado pastando.-19. Por el crimino.

Acuarelas, 1951 :

20. Apunte del Canal de Churubusco-21. Por las Lomas de Contreras.

Dibujos, 1951 :

22. Desde el Tepeyac.--23. El Desfile---24. Bosquejo.

* Elaine Hamilton O'Neil-Exposición de pintura presentada por la Galería de Arte Moderno, Plaza Sintos Degollado, 16-C y D. Desde el 18 de enero.

* José Feher.-Exposición de pintura presentada por la Galería de Arte Mexicano, en su local de las calles de Milán, 18. Del 21 de enero al 15 de febrero.

1. Circo.--2. En la tarde.-3. Naturaleza muerta.-4. Frutas maduras.-5. La 1amaca.-6. Mi hijo en su caballito de cartól1-7. Desnudo--8. Los yericos.-y. Campo de concentración-10. Acapulco.-11. Casa azul-12. Casas y árboles..13. Callejón-14. Otoño.-15. Autorretrato.-16. Octubre--17. En la mañana. 
Gouaches :

18. Casas en Francia.-19. La casa rosa.-20. Casa de la provincia francesa.-21. Casas e iglesia.--22. Naturaleza muerta.

Dibujos :

23. Desnudo.-24. Retrato de mi esposa.-25. Autorretrato.-26. Pequeño puebl, liúngaro.-27. Saint Malo.-28. Autorretrato.-29. Mástil.-30. Campesina.-31. Desnudo.-32. Desnudo.-33. Desnudo.-34. Desnudo

Esculturas:

35. El Vencedor, 1918. Cerámica esmaltada.-36. Madre e hijo. 1945. Cerámica esmaltada.-37. Miedo, 1952. Terracota.-38, Jarra. Terracota.-39. Niño con máscara. Ceráınica.

Ceránica :

50. Platos.

* Fernando Marcos y Osvaldo Reyes_-Exposición de pintura y dibujo, presentada por la Galería de Arte Moderno en su local de Plaza Santos Degollado, C. y D. Del 23 de enero al 12 de febrero.

\section{FEBRERO}

* Sociedad Mexicana de Grabadores.-Exposición de grabado presentada con motivo del homenaje rendido al genial grabador José Guadalupe Posada, en el primer centenario de su natalicio, en la casa núm. 47 de las calles del Carmen. El 2 de febrero.

* Martha Watson Sauer.-Exposición de pintura presentada por el Instituto Mexicano-Norteamericano de Relaciones Culturales, en Yucatán, 63. Del 6 al 16 de febrero.

1. E1 Prado, Habana. (Premiada).-2. Patio. Roi Christophe, Cap Haitien, Haiti3. Miss Pilliner's Guesthouse, Kingston, Jamaica.-4. On Whitehead Street, Key West.-5. Coconut Vendor. Kingston, Jamaica.-6. Bois Jalousie. Petionville, Haiti.-7. Pink House. Petionville, Haiti.-8. Iones Street House. Savannah, Georgia.-9. Boat House. Magnolia Springs. Alabama_-10. At the Beach.-11. Miss Albury's House. Key West.-12. Vegetable Man. New Orleans.-13. Road to the Springs. Hope Bay, Jamaica.-14. At Hope Bay. Tamaica.-15. At Tete de L'Eau. Petionville, Haití-16. Back Yard. Jamaica.--. 17. Key West Home.-18. In Garden Section. New Orleans.-19. Love Lane. Key West.-20. Coconut Harvest.-21. In Patzcuaro.-22. Patzcuaro Market.23. Casa de Alvarado, Cosoacán.-24. Shadows on the Techa. New Iberia. 
(La Premiada).--25. Carenage. Cap. Haitien, Haiti--26. Home in Port Antonio, Jamaica.-27. Le Joli Clos. Petionville, Haiti.-28. Tennessee Autumn.29. Market. Cap. Haitien, Haiti-30. Bus Terminal. Port au Prince, Haiti. -31. Back of the Humboldt House. Tasco.-32. Pilgrims to Guadalupe.-33. Spanish Laurel. Key West.-34. Patio, Matilda Grey Residence. New Orleans.

* Galería Reger.-Exposición de jintura de Haiti, patrocinada por la Embajada de Haití y presentada en Lisboa, 60. Desde el 7 de febrero al 13 de marzo.

Abelard, Gesner: 1. Mercado Valliéres, Puerto Príncipe-Alix, Gabricl: 2. Flores. -Ambroisc, Ulrick: 3. Danza popular.-Amiama, Xavicr: 4. Nocturno.Auguste, Toussaint: 5. Pájaros.-6. Combite-Bazile, Castera: 7. Baile de antaño.-8. Pelea de gallos.-Bcnoit, Rigaud: 9. Rey de Africa-Bigaud, 11.ilson: 10. El accidente-Borno, Maurice: 11. El hombre del gallo.-Cedor, Dicudonné: 12. El filósofo desgraciado.-Domond, Wilmino: 13. El parto.Dorcely, Roland: 14. Naturaleza muerta.-15. Voudouesque.-Doucet, Rita: 16. Pablito.-Dufout, Préfete: 17. Ciudad imaginaria.-Dupoux, Raoul: 18. Paisaje.-Emile, Denis: 19. El huérfano-- Fustache: 20. El jugador de dados.Francois, Edgard: 21. Paisaje--Gourgue, Enguerrand: 22. Himno a la libertad--Hyppolite, Hector: 23. Mujer y pájaros.-Jacob, Joseph: 24. Ceremonia vodú.-Ioscph, Antonio: 25. Bel-Air. Puerto Príncipe-Joseph, Jasmin: 26. Reunión de gatos.- Lafortunc, Danicl: 27. Vendedora de pescado.-Lazare, Luckner: 28. En el mercado.-Lcfeirc, Gabricl: 29. Las ondinas.-Lcontus, Adam: 30. Los revolucionarios.-Malebranche, Elaire: 31. E1 dios Grédé.Obin, Philonć: 32. Deporte escolar-Pascal, Pierre: 33. Retrato-Pinchinat, Max: 34. Mi muñeca negra.-Saint-Brice, Robert: 35. Flores.-36. Niño.Poisson, Louverture: 37. Naturaleza muerta.-38. E1 árbol mágico.-39. Drama pasional.-Price, Lucicn: 40. Formas arcaicas.-41. Estudio.-Turnicr, Luce: 42. La lámpara-Vincent, Joseph: 43. El calvario del Cabo Haitiano.

* Primera cxposición anual de artjstas plásticos mexicanos y españoles residentes en México, presentada en el paheluín de "La Flor", en el bosque de Chapultepec. Desde el 12 de febrero.

* Josí Clemente Orosco.-Exposición de 7 gouaches y dibujos, presentada en la Galeria de Arte Contemporáneo, Anberes 12 y Reforma. Del 15 de febrero al 1o. de nuarzo.

* Ccforino Colinas.-Exposicioin de esculturas presentada por el Instituto Nacional de Bellas Artes, en la Logia Oriente del Museo Nacional de Artes Plásticas. en el Palacio de Bellas Artes. Desde el 18 de febrero.

* Charles Michel.-Exposición de pintura patrocinada por el Enviado Extraordinario y Ministro Plenipotenciario de su M. el Rey de Bélgica, en México. Excmo. Sr. D. Walter Loridan y presentada por la Galería de Arte Mexicano en su local de las calles de Milán, 18. Desde el 18 de febrero. 
* Centro de Arte Mexicano Contemporáneo.-Exposición de la Estampa cubana, presentada en Toluca, Méx., en el Museo de Bellas Artes. Del 23 de febrero al 22 de marzo.

Expositores :

Ana Rosa Gonálä, Armando Posse, Armando Fernándes, Angel Marti, Alberto Menchaca, A. Cárdenas, Carmelo Gonzáles, Enrique Caravia, Eugenio Rodriguez, Holbein López, Israel Córdoba, José Lópea, Luis Peñalver, Manolo Fernández, Raúl Hernández, Rolando Santana, Rolando Gutiérrez.

* Celia Calderón.-Exposición de pintura presentada por el Salón de la Plástica Mexicana, Galería de Ventas Libres. Del 25 de febrero al 24 de marzo.

Pinturas 1951-1952:

1. El Mercado.-2. El Torito.-3. Noche de Muertos en el Tepozteco.-4. El Periquito.-5. El Periquito.-6. Paisaje.-7. Niña con una flor.-8. El Avión.-9. Terror.-10. La Ventana.-11. Bañistas.-12. Aguadora de Tetelzingo.-13. Aguadora de Tetelzingo.-14. Mamita linda.--15. Paisaje.

Acuarelas 1951-1952:

1. Arboles en Yautepec.-2. Aguadora de Tetelzingo.-3. Aguadora de Tetelzingo. 4. La carta.-5. Bañistas.-6. El Avión.-7. La Ventana.-8. El Perico.-9. Cabeza.-10. Lluvia.

Dibujos 1951-1952:

1. Cabeza de viejo. Tinta.-2. Cabeza de muchacha. Tinta.-3. Cabeza de muchacha. Tinta.-4. Estudio de Cabeza. Lápiz.-5. Terror. Tinta.

Estampas 1951-1952:

1. Niña con una flor. Agua tiuta.-2. Por caridad. Punta seca.-3. Mujer cosiendo. Agua tinta.-4. La ventana. Litografía.-5. Cabeza. Grabado en madera.

$M A R Z O$

* Erasto Cortós Juárcz.-Exposición de grabados presentada por el Centro de Arte Mexicano Contemporáneo, en la Sala de Arte del Centro, República de Cuba, 75. Del 1o. al 31 de marzo.

1. Mi Madre.-2. Aguadores de Tepeaca-3. Los Remedios-4. Platanares de Uruapam.-5 Limosnero de Tlacolula.-6. Casas de Puerto Príncipe, Haití- 
7. Mercado de Puerto Príncipe, Haiti.-8. Negros de Haití.-9. Calle de Uruapan.-10. Tirada de la fruta, Juchitán, Oax.-11. Mujer de Jicalan, Mich.12. José G. Posada, Viñeta.-13. Serie "Los Músicos" Shuman, Mozart, Bach, Meudelson, Berlioz, Shubert, Haydn, Clopin, Haendel, Corelli, Palestrina, Beethoven.-14. Carátula para el portafolio serie "Los Músicos".

* Raúl Anguiano.-Exposición remate de toda su obra, presentada en la Galería de Arte Mexicano, Milán 18. Del 10 al 20 de marzo.

* Mexico City College.-4a. Exposición anual de pintura, joyería, diseño, escultura, serigrafía, grabado, fotografía y dibujo, presentada en el No. 132 de la calle de San Luis Potosí. Desde el 10 de marzo.

* "Novedades" y el suplemento "México en la Cultura".-Exposición titulada "De Carnavales a Judas en la Pintura de México", presentada en la Galería de Arte Contemporáneo. Desde el 20 de marzo.

* Andrés Salgo.-Exposición de pintura presentada por la Galería de Arte Moderno, Plaza Santos Degollado, 16-C y D. Desde el 24 de marzo.

* Mathias Goerits-Exposición de escultura presentada por la Galería de Arte Mexicano, en su local de las calles de Milán, 18. Del 27 de marzo al 30 de abril.

Pinturas :

1. Noche humana. 1950. Oleo. $29 \times 47 .-2$. La-Bas. 1951. Tinta y gouache. $70 \times$ 103.-3. Calvarios. 1951. Tinta $y$ gouaclee. $42 \times 71$-4. Figura tropical. 1951. Duco y gouache. $76 \times 56$.-5. Encuentro místico. 1952. Duco y gouache. 76 $x$ 56.-6. Rudinnentos. 1952. Tinta y gouache. $57 \times 77-7$. Dibujo. 1949. Tinta. $23 \times$ 16.-NOTA: todas las medidas son en centínetros.

Esculturas:

8. Amantes. 1950. Madera (parota). $36 \mathrm{~cm}$. de largo.-9. Pez. 1950. Maderá (parota). $46 \mathrm{~cm}$. de ancho.-10. Pájaro. 1950. Madera (parota). $47 \mathrm{~cm}$. de ancho. 11. El otro animal. 1950. Fierro fundido. $105 \mathrm{~cm}$. de largo.-12. Hombre. 1950. Madera (parota). $39 \mathrm{~cm}$. de alto.-13. Cabeza. 1950. Bronce. $18 \mathrm{~cm}$. de alto.-14. La Mujer de cinco caras. 1950. Cantera policromada. $62 \mathrm{~cm}$. de alto.-15. Mujer. 1950. Relieve de cantera, policromado. $45 \mathrm{~cm}$. de alto.16. Máscara triste. 1950. Madera (ocote), policromada. $52 \mathrm{~cm}$. de alto.- -17 . Madre con niño. 1951. Madera (parota). $32 \mathrm{~cm}$. de alto.-18. Maniquí, 1951. Madera (cedro). $93 \mathrm{~cm}$. de alto-19. Monumento. 1951. Relieve de madera (sabino), policromado. 105. cm. de largo.-20. Pareja. 1951. Madera (nogal). $38 \mathrm{~cm}$. de alto.-21. Pareja alegre. 1951. Madera (parota). $73 \mathrm{~cm}$. de alto. -22. Estirpe. 1951. Madera (parota). 79. cm. de alto.-23. Ternura. 1951. Bules. $29 \mathrm{~cm}$. de ancho.-24. Bailarin. 1951. Madera (parota). $76 \mathrm{~cm}$. de alto.-25. 
Bailador. 1951. Madera (sabino). $69 \mathrm{~cm}$. de alto.-26. El animal herido. 1951. Madera (sabino). $61 \mathrm{~cm}$. de alto.-27. Visionario. 1951. Piedra volcánica. $35 \mathrm{~cm}$. de alto.-28. Dos amantes. 1951. Madera (ébano). $41 \mathrm{~cm}$. de alto,-29. Crucifijo. 1951. Madera (parota). $67 \mathrm{~cm}$. de alto.-30. Salvador de Auschwitz I. 1951. Madera (parota). $52 \mathrm{~cm}$. de alto.-31 Salvador de Auschwitz II. 1951. Madera (parota). 85. cm. de alto.-32. Salvador (le Auschwitz V. 1951. Madera (parota). $132 \mathrm{~cm}$. de alto.-33. Salvador de Auscliwitz VII. 1951-52. Fierro forjado. $345 \mathrm{~cm}$. de alto.-34. Cero. 1951-52. Madera (Mezquite). $54 \mathrm{~cm}$. de ancho.-35. Moisés. 1952. Madera (nogal). $82 \mathrm{~cm}$. de alto.-36. Cóncavo y convexo. 1952. Madera (sabino). $59 \mathrm{~cm}$. de alto.-37. Mi Mano. 1952. Madera (sabino). $39 \mathrm{~cm}$. de alto.

* Josí Guticrrez-Exposición de pinturas presentada por el Salón de la Plástica Mexicana, Galería de Ventas Libres, del Instituto Nacional de Bellas Artes. Del 31 de marzo al 28 de abril.

1. El Péndulo. Piroxilina y vinilita. $130 \times 122 .-2$. Girasol. Piroxilina y vinilita. $120 \times 89 .-3$. El caballito. Piroxilina $y$ vinilita. $122 \times 92.4$. El cos. Vinilita. $107 \times$ x 80.-5. Germinación. Vinilita y piroxilina. 81. $x$ 99.6. Silencio. Piroxilina. $102 \times 81 .-7$. El Vielo del Moscardón. Piroxilina $y$ vinilita. $122 \times 89 .-8$. La Ciudad de día $y$ de noche. Piroxilina $y$ vinilita. $122 \times 89 .-9$. Torito. Piroxilina. $122 \times 100,-10$. El Trueno. Piroxilina $\mathrm{y}$ vinilita. $122 \times 92 .-11$. Sueño $\mathrm{y}$ realidad. Piroxilina y vinilita. $122 \mathrm{x}$ 106.-12. Ejercicio plástico. Piroxilina y vinilita. $81 \times 99 .-13$. Firego. Piroxilina $y$ vinilita. $102 \times 81 .-14$. Henequén. Piroxilina. $115 \times 89 .-15$. El Yurque. Piroxilina. $102 \times 81$-16. Apocalipsis. Piroxilina. $122 \times 122 .-$ NOTA: Todas las medidas son en centímetros.

ABRIJ.

* Desiderio Hernánder Xochitiotsin.-Exposición de sus treinta últimas obras sobre el tema "Carnavales" de Hucjotzingo, San Felipe Hueyotlipan, Pue., Contla y Tapalotla de Tlaxcala, realizadas a jluma $y$ tinta china sobre papel por encargo del señor presbítero don Carlos Vera para una exposición que con el título de "Carnavales Mexicanos", recorrerá las ciudacles de Los Angeles y San Francisco, California, Washington, D. C. Nueva York y otras capitales de los Estados Uni‘los, y presentada en su Sala Estudio ubicada en el "Barrio del Artista" de Ja ciudad de Puebla. Del 12 al 19 de abril.

* Edwin Boyd Johnson.-Exposición de fotografías presentada por el Insti1uto Mexicano-Norteamericano de Relaciones Culturales, presentada en su Auditorium. Yucatán 63. Desde el 14 de abril.

* Clara Porset.-Exposición titulada "El Arte en la Vida Diaria" de objeios le buen diseño heclıos en México, presentada por el Departamento de Arqui- 
tectura del Instituto Nacional de Bellas Artes, en las Salas Bellas Artes y de la Estampa del Palacio de Bellas Artes. Desde el 17 de abril.

* José Luis Aguerrebere-Exposición de pintura presentada por la Galería de Arte Moderno, Plaza Santos Degollado, 16 C. y D. Del 18 de abril al 8 de mayo.

* Instituto Nacional de Antropologia y Dirección del Museo Nacional de Antropología.-Exposición de la "Cultura Egipcia", presentada con motivo de la inauguración de la Sala de Exposiciones Temporales de dicho Museo, con las valiosas colecciones proporcionadas por el Museo Metropolitano de Nueva York, U. S. A. Desde el 21 de abril.

* Instituto Nacional de Bellas Artes.-Exposición titulada "Arquitectura Popular Mexicana", organizada por su Departamento de Arquitectura y presentada en la Sala Nacional del Palacio de Bellas Artes. Desde el 21 re abril.

* Patronato de las Artes e Industrias Populares.-Exposición de Platería Popular Mexicana, presentada en el Museo de Artes e Industrias Populares, Avenida Juárez, 44. Desde el 28 de abril.

$M A Y O$

* Excelsior.-Exposición de pinturas, arreglos florales y Plantas cultivadas, titulada "Fiesta de la Flor" y organizada con el patrocinio del señor licenciado Miguel Alemán, Presidente de la República y de don Nazario Ortiz Garza, Secretario de Agricultura, presentada en el Bosque de Chapultepec, junto al Museo de la Flora. Desde el 3 de mayo.

* Instituto Nacional de Bellas Artes.-Exposición de pintura contemporánea, con fines comerciales, presentada en el Salón de la Plástica Mexicana, Galería de Ventas Libres. Del 6 al 30 de mayo.

\section{Expositores :}

Ignacio Aguirre, Raúl Anguiano, Celia Calderón, Federico Cantú, Fernando Castro Pacheco, Olga Costa, José Chávez Morado, Arturo García Bustos, Maria Izquierdo, Amador Lugo, Ricardo Martínez, Guillermo Meza, Gustavo Montoya, Nicolás Moreno, Luis Nishizawa, Carlos Orozco Romero, Feliciano Peña, Fanny Rabel, Rufino Tamayo, Cordelia Unueta, Alfredo Zalce.

* Suzanne Daco de Genachte.-Exposición de grabados presentada por la Galería de Arte Moderno, Plaza Santos Degollado 16 C y D., y patrocinada por el Ministro de Bélgica en México, Exmo. señor Walter Loridan. Del 7 al 27 de mayo. 


\section{Maderas:}

1 a 13. Ilustraciones para libros.-14. Janitzio.-15. Guanajuato--16. Panorama de Taxco.-17. Bélgica: desfile de gigantes.-18 a 22. Participaciones.-23 y 24. Tarjetas de Navidad.-25. Ex-libris.-26. Gato.-27. Gato.-28. Panorama de Cuernavaca.-29. Kermesse en Brabante.-30. Jardín en Cuernavaca.-31. Marfil, Gto.-32. Perro.-33. Calle Malmédy, Bélgica.-34 y 35. Hacienda en Bélgica. Maderas en color.

Punta secas:

36. Tanitzio: Día de Muertos.-37. Caballo.-38. Desnudo.-39. Desnudo--40. Casa en Nueva Orleans.-41. Norteño-42. Chapultepec--43. Torres de Brujas.

Aguafuertes :

44. Paisaje de Brabante-45. Puerto de Acapulco.-46. Puerto de Acapulco. Aguatinta.-47. Desnudo. Aguatinta.-48. Casas de Cuernavaca. Aguatinta.-49. Templo en Cuernavaca. Aguatinti.-50. Escena de París. Barniz suave.

\section{Litografías :}

51. Voladores de Huauchinango.-52. Acapulco.-53. Panorama de Oaxaca.-54. Lago de Pátzcuaro.-55. Calle en Nueva Orleans.

* Mariano Paredes.-Exposición de sus últimas obras presentada por la Galería de Arte Moderno, Plaza Santos Degollado, 16. Del 9 al 31 de mayo.

* Angelina Beloff.-Exposición remate de pinturas, dibujos y grabados, presentada en la Galería de Arte Mexicano, Milán, 18. Del 26 al 5 de junio.

* Ramón Alva de la Canal.-Exposición de pinturas presentada en la Galería de Arte de la Librería Iuárez, Avenida Juárez, 102. Del 27 de mayo al 10 de Tunio.

1. Autorretrato. Oleo.-2. Retrato del esciltor Germán Cueto. Oleo.-3. La Ventana. Dibujo.-4. Retrato. Dibujo.-5. El Movimiento Estridentista. Oleo.6. Cortadoras de Café. Acuarela.-7. El Viajero en el Vértice. Grabados. -8. Vendedora de Cereales. Acuarela,-9. Botes de Pintura. Oleo.-10. El Poeta Yucateco. Oleo.-11. Damas y Abanicos. Oleo.-12. Estudiantes. Oleo. 13. Bailarinas. Oleo-14. El Cenote. Acuarela.-15. Paisaje. Acuarela.-16. Paisaje. Acuarela.-17.. Amecameca. Acuarela.-18. Lavandera. Acuarela. 19. Paisaje. Acuarela.-20. Vendedora de Cereales. Acuarela.-21. Leobardo. Oleo.-22. Morelos. Carbón.-23. La Espulgadora. Oleo. 24. Estudio de Mujer (para la decoración del inonumento a Morelos en Janitzio, Michoacán).-25. Naturaleza Muerta. Oleo.-26. La Virgen del Pue- 
blito. Oleo.-27. Mujeres Yucatecas. Oleo.-28. El Dtuch. Oleo.-29. Cabina. Dibujo.-30. Danzante de la Villa. Oleo.-31. Rosa María. Pastel-32. Martha Maria. Oleo.-33. Paisaje de Guerrero. Oleo.-34. Paisaje. Pochoir.-35. Eleonora. Oleo.-36. Retrato. Oleo.-37. Mireya. Oleo.-38. Retrato. Oleo.39. Bodegón. Oleo.-40. Dama con flor. Olco.41. Naturaleza Muerta. Oleo42. Retrato. Oleo.43. Niña de la Mariposa. Oleo.-44. Los Danzantes. Oleo. 45. Dibujo de Niño.-46. Apunte-47. Interior. Oleo.-48. Fiesta. Oleo49. Los Turistas. Oleo.-50. La Máscara. Oleo.-51. Retrato. Oleo.-52. Muchachas. Oleo.-53. Gentes del Pueblo. Oleo. 54. Don Ignacio López Rayón. Oleo.-55. Proyecto para una decoración nural. Dibujo.-56. La Danza de los Viejitos. Oleo.-57. Sinfonía Jubilosa. (Jlustraciones).-58. Fotografías de los murales ejecutados en los talleres de la Marina Nacional.

$1(N / O$

* Parboo Singh,--Exposición de pinturas presentada por el Jnstituto AngloMexicano, en Pánuco No. 10. Del 3 al 17 de junio.

!. Viva la Revolución.-2. Terror-3. Pescadores.-4. Baile de Máscaras de San Carlos.-5. Uno entre tantos.-6. Una familia frente a la muerte--7. Candidato del pucblo.-8. Dos amantes.-9. La Alameda.-10. Madre e hijo.-11. ¿Adónde vamos?-12. Paseo de la Reforma.-13. Retrato de Mujer.-14. Siesta.-15. Vista desde el taller.-16. Fotógrafo.--17. Atributos del taller.-18 El hombre y su ambiente.-19. La Esperanza.

Dibujos:

20. Cabeza de niño.-21. Los basureros.

* Lester Epstein.-Exposición de pintura y dibujo presentada por el Instituto Mexicano-Norteamericano de Relaciones Culturales, Yucatán, 63. Del 5 al 20 de junio.

Gouaclies :

1. Alcancía.--2. Family Group.-3. Serenade To Siska.-4. Lovers.-5. Sleeping Child. -6. In Bed.-7. The Beach.-8. Poet.-9. Blue Head.-10. Conspiracy.-11. Loom.--12. Head.

Dibujos:

1. Newsboys,-2. Consulting The Oracle.-3. Sinister Structure.-4. Picador.-5. Puppet.-6. Discreet Structure No. 1.-7. Discreet Structure No. 2.-8. Ritual. 9. Defeat.-10 Criada.-11. Escape From The Gibbet.-12. Matador--13. Shards-14. Defercnce To A Former Godhood.-15. Matinee-16. The War- 
riors,-17. E.ffort To Avoid Sorrow By Buffoonery No. 1.-18. Effort To Avoid Sorrow By Buffoonery No. 2.-19. Effort To Avoid Sorrow By Buffonery No. 3.-20. Effort To Avoil Sorrow By Buffoonery No. 4.-21. Apparition.-22. Incantation,-23. Dove.-24. Net Forms, La Ventosa No. 1.-25. Net Forms. La Ventosa No. 2.-26. The Learned Astrmomers.27. Oaxaca Bus, 28. Orators.-29. El Salón México.-30. Fishermen.-31. Kneeling Warriorts. -32. Torso.-33. Girl Whith a YoYo.-34. Dressmaker.-35. Marionette-36. in The Nest No. 1.-37. In The Nest No. 2.-38. Suspended Objects.-39. Duo, 40. Defender Of The Isthmus,-41. Polonius And Laertes.-42. Night Watcin At Elsinore.

* Itsús Ortiz Tajonar-Exposición le pintura presentada por la Galería Arte Moclerno, Plaza Santos Degollado, 16 C y D. Del 6 al 26 de junio.

1. Paisaje de San Jerónimo. Oleo. $35 \times 31$-2. Lavanderas en el Río Xotepingo. Oleo. $50.5 \times 49.5$. -3. Parque Revolución de Cuernavaca. Oleo. $38 \times 29-$ 4. Alrededores de Contreras. Olco. $67 \times 51 .-5$. Cerros de San Joaquín. Oleo. $0.5 \times 49.5,-6$. Lavanderas en Tlalpan. Oleo. $64 \times 49.5 .-7$. Camino de Coutreras. Oleo. 78. $\times$ 55.-8. La Coconetla. Oleo. $56 \times 49.5$.-9. Camino de Churuhisco. Oleo. $69 \times 52 .-10$. Los Coxconates. Oleo. 76. x 41.-11. Naturaleza riucrta. Oleo. $45.5 \times 39 .-12$. Vendedora de Cempasúchil. Oleo. $60 \times 50 .-13$. E1 niño del banco. Oleo. $50 \times 40$ - 14. Cañero de las Amilpas. Temple. $136 \times$ 4.-15. Niño campesino. Oleo. $90 \times 64 .-16$. Zapalistas. Oleo. $90 \times 74 .-17$. Retatu de Campesino. Temple. 69.5 x 48.-18. Desolación. Oleo. 62 x 44.-10. El centinela. Piroxilina. $1.16 \times 83$-20. La riña. Piroxilina. $37 \times 27.5$. 21. El Apóstol del Agrarisno. Tenple. $182 \times 122$-22. Tres figuras con esfera. Oleo. $72 \times 65.5 .-23$. Tortillería de barrio. Oleo. $50 \times 40 .-24$. Retrato de mujer. Oleo. $82.5 \times$ 56.5.-25. Carmen. Oleo. $98 \times 29 .-26$. Maternidad. Oleo. $65 \times$ 46.5.-27. Yolandita. Oleo. $75 \times 59.28$. Clarita. Oleo. $70 \times 50 .-29$. Autorretrato. Oleo. $67 \times 50 .-30$. La mujer del chal negro. Oleo. 61 x 50.5. NOTA: Todas las medidas son en centímetros.

* Clea Gaston-Exposición de serigrafías, presentada por la Galería de Arte Moderno, Plaza Santos Degollado, $16 \mathrm{C}$ y D. Del 6 al 26 de junio.

1. Decier1o de Jos Leones. $1950.14 \times 15 .-2$. U'n paisaje de árboles, $1950.14 \times 15 .-$ 3. E1 retrato de una mujer. $1949.11 \times 13.4$. Un ramo surtido. $1948.8 \times$ 13.-5. Admiración. 1949. $12 \times 13$-6. El Hombre con sombrero de paja. 1949. $15 \times 20 .-7$. Los Arboles. 1951. $19 \times 22$ × -8. Al Anochecer. 1951. $13 \times 21$.\%. Alcatraces. 1951. $14 \times 25 .-10$. Claveles. 1951. $12 \times 16 .-11$. El Parque. 1951. $12 \times 20 .-12$. El Popocatépetl en la noche. 1951. $4 \times 23 .-13$. Fue en la carretera. 1951. $3 \times 18 .-14$. En el campo. 1951. $15 \times 15 .-15$. Haciendo sus trcnzas. 1951. $8 \times$ 12.-16. Los Hermanos. 1951. $10 \times 10 .-17$. A1 Oeste de 1a Ciudad. 1951. $13 \times$ 29.-18. La Puesta del Sol. 1951. 2 × 30.-19. Fue un simbolo de amistad. 1951. $13 \times 19$-20. La Tehuana. 1951. $8 \times 9 .-21$. E1 Monte. 1052. $12 \times 17 .-22$. Un paisaje. 1952. $12 \times$ 17.-23. Niño en la Primavera. 
1952. $15 \times$ 15.-24. Madre e Hijo. 1952. 13 x 17.-25. Los Pedregales. 1951. $2 \times 29$ - 26. Los Girasoles en vida. 1950. $20 \times 20$.- NOTA: Todas las medidas son en centímetros.

* Michael Baxter.-Exposición de pintura presentada por la Galería de Arte Mexicano, en su local de las calles de Milán, 18. Desde el 9 de junio.

* Macias Báez.-Exposición de las láminas de estudio que sirvieron de base para el vestuario del Ballet Bonampak, presentada por el Ateneo de Chiapas en la Galería de Arte Contemporáneo, Amberes 12. Desde el 13 de junio.

* Centro de Arte Mexicano Contemporáneo-Exposición colectiva de estampas en color, presentada en la Sala del Centro ubicada en República de Cuba, 75. Del 14 de junio al 12 de julio.

Expositores :

G. Casillas Larios, Jorge Cházes, Mariano Paredes, Guillermo Gonsález.

* Exposición (liomenaje a Vicente Lombardo Toledano), de pintura, escultura, grabado y fotografía, presentada en Sadi Carnot, 44. Del 20 de jumio al 25 de julio.

Pintores :

David Alfaro Siqueiros, Diego Rivera, Jorye González Canarena, Jesús Guerroro Galván, Ignacio Aguirre, Federico Silva, Roberto Verdesio, Angel Bracho, Pablo O'Higgins, Tanny Ravel, Luis Arenal, Luis Covarrubias, Agastin Villarra, Alfonso Michel, Juan Madrid, Francisco Mora, Jesís Escobedo, Angel Maldonado, Juan González, Roberto Acuña, Humberto Valencia, Raymundo $S$. Alemán, Joel Marroquin y Miguel Cozarnbias.

Escultores:

Federico Canessi, Givillcrmo Toussaint, Ramiro Gabiño.

Grabadores :

Leopoldo Méndez, Alberto Beltrán, Andrea Gómez, M. Jimíncz, Francisco Dosamantes, Mexiac.

Fotógrafos:

Manuel Aivarez Bravo, Luisa Mayo Altamirano.

* Escuela de Pintura y Escultura de Esmeralda y Ancxo de Coyoacán.-Exposición de Pintura y escultura de los trabajos ejecutados por los pintores y escul- 
tores veteranos norteamericanos, presentada en la Biblioteca Cervantes. Del 27 de junio al 7 de julio.

Expositores :

Walter Bachrach, Manuel Bennett, Paul Berkc W., Judson Brigs, Nelson Capulliez, Morton Dimondstein, Lester Epstein, Sidney Geist, Mario D. Giozangelo, Morris Gorovitz, George Grumblat, Jim Homey, Ediwin Johnson, Moc Leibovitz, David León, Malcolm A. McClain, Ed Macy, Ernest Martin, John Martenstein, Iid Mix, Robert S. Miyasato, Paul Morgan, Ton Morphy, James Parsons, Dave Palock, Bert Pumphrey, Ed Ruda, Ignoscencio Vásquez G., Dan Welsh, Hugh Wiley, David Williams.

* L'Art Pictural de Paris y Galería Arte Moderno.-- Exposición titulada "Pintores de la Escuela de París", presentada en el local de Plaza Santos Degollado, $16 \mathrm{C}$ y D. Del 27 de junio al 17 de julio.

Oleos :

Beaulieu: 1. Naturaleza muerta.-2. Naturaleza muerta.-3. Naturaleza muerta.-Barón Renouard: 4. Paisaje.-5. Vendedora de flores.-6. Barcas.-7. Arboles. -Yvette Alde: 8. Gato y pescados.-9. Ramo de flores.-Paul Charlot: 10. El puerto-Forisier: 11. El Rhone-12. Jardín de Luxemburgo.-Tronel: 13. Jardlín.-14. Balcón.-15. San Genis.-Finazai: 16. Rouen.-Hilaire: 17. San Tropez-Wogensky: 18. Paisaje.-Montañana: 19. Rincón de París.-20. E1 viejo París.-Suáres: 21. Paisaje.-Mayou Iserentant: 22. Los Pirineos.-Alfonso Garcia: 23. Paisaje tropical.-24. Frutero.-25. El jarro roto-26. China poblana. (Retrato de la danzarina Irma Orozco).

Grabados (aguafuertes):

Pablo Picaso: 27. Artista con sus obras.-28. Estudio de cabeza y destu1do.-G. Rouanlt: 29. Polinesio.-Dunoyer de Segonaac: 30. La toilette-Signac: 31. Puente de las artes. (París).-Suranne Valadon: 32. El baño.-Peinado: 33. Retrato de niño.-Pedro Flores: 34. Maja y torero.

* José Guadalupe Posada-Exposición Homenaje de cien de sus grabados, presentada por La Peña de Amigos del Arte, en ocasión del Primer Centenario cle su natalicio, en la Sala Estudio del pintor Desiderio Hernández Xochitiotzin. Barrio del Artista de la ciudad de Puebla, Pue. Desde el 28 de junio.

* Eduardo Hernánder Xochitiotzin-Exposición de su últinua obra "Presencia del Torerillo Ausente", monotipo estampado sobre tela blanca, presentada por la Unión de Artes Plásticas en la Sala de la Obra Semanal, Estudio Número 1, 8 Norte, 407, de la ciudad de Puebla, Pue. Del 28 de junio al 4 de julio. 
JULIO

* Infante Velázquez.-Exposición de pintura presentada en el Kiosco de la Alameda Central. Del 5 al 25 de julio.

Temple :

1. El Nopal Negro.-2. El Nopal Rojo.-3. Legumbres.-4. Paisaje.

Gouache :

5. Herramientas.-6. Herramientas.-7. Herramientas.-8. Herramientas.-9. Naturaleza.-10. Naturaleza.-11. Naturaleza.-12. Naturaleza.-13. Naturaleza.14. Naturaleza.-15. Naturaleza.-16. Maceta.-17. Maceta.-18. Calavera,-19. Calavera.-20. Calavera.-21. Calavera.-22. Cristo. Crayuela.-23. La Madona. Pastel.-24. Retrato. Pastel.-25. Calabaza. Pastel.-26. Retrato. Dibujo.

* Celia Calderón.-Exposición de pinturas y dibujos, presentada por The British Council, en Pánuco 10. Del 15 al 29 de julio.

Pinturas:

1. El mercado.-2. El periquito.-3. El periquito.-4. Niña con una flor--5. El avión.-6. Terror.-7. La ventana.-8. Bañistas.-9. Bañistas.-10. Aguadora de Tetelzingo.

Acuarelas :

1. Ia carta.-2. Bañistas.-3, El avión.-4. La ventana.-5. Azoro.-6. Lluvia.-7. London Bridge.-8. Tube station.--9. Una calle en invierno.-10. Arboles.-11. Cabeza.

Estampas:

1. Niña con una flor. Agua tinta.-2. Por caridad. Punta seca.-3. Mujer cosiendo. Agua tinta.-4. Azoro. Litografía,-5. Cabeza. Grabado en madera.

Dibujos:

1. Terror. Tinta.-2. Cuatro estudios a lápiz.--3. Nueve estudios a tinta.-4. Estudio. Sanguina.

* Enile Roure.-Exposición de pinturas presentada por el Instituto MexicanoNorteamericano de Relaciones Culturales, en el Auditorium de Yucatén, 63. Del 17 al 31 de julio. 
Oleos:

1. Viejo. $55 \times 55 .-2$. Alameda. $60 \times 75 .-3$. Pueblo en las Montañas. $90 \times 90,4$. Ixtaccíhuatl. $60 \times$ 75.-5. Mucliacho de Amecameca. 55 x 55.-6. Redheads. $90 \times 90 .-7$. Yola. $50 \times 55 .-8$. Mercado de Taxco. $75 \times 90 .-9$. Las Casas, Santo Domingo. $90 \times 90 .-10$. Taxco. $75 \times 90 .-11$. Carmen. $50 \times 55 .-12$. Callejón. $60 \times 75 .-13$. Yucatán. $75 \times 90 .-14$. Los Vendedores. $55 \times 55$.--NOTA: Todas las medidas son en centímetros.

* Richard A. Florsheim.-Exposiciún de litografías presentada por el Instituto Nacional de Bellas Artes, en la Sala de la Estampa del Museo de Artes Plásticas, Palacio de Bellas Artes. Del 18 de julio al 17 de agosto.

Litografías propiedad del artista.

De la Serie de la Guerra:

1. Así fué como empezó todo... 1940. $36.5 \times 25.5 .-2$. . . el viento pasó entre los árboles desnudos ... 1940, $32.5 \times 43,-3, \ldots$ sobre las rocas que defendían a las ramas tronchadas... 1940. $15.5 \times 26.4$. ... en costas cargadas de huratcanes. 1940. 15 x 43.-5. Se alejaron de donde él cayó... 1940. 16.5 x 29.6 6 . ... minientras las visiones le agobiaban, destrozado $y$ silencioso. 1940. $26.5 \times 15.5$. 7. ... el combatiente no veía las caras de los otros. 1940. $24 \times 34 .-8 . \ldots$ in marchaba a ritmo a través de la oscuridad creciente... 1940. 50 x 37.-9. . . y vagaba sin hogar. 1941. 24.5 × 31.5.-10. Pasó el viento despedazando ramas. 1944. $33 \times 23.5$.-11. Símbolos extraños permanecían en las playas... 1944. $23.5 \times 34 .-12$. ... mientras figuras sombrías buscaban. 1944. $25 \times 35.5 .-13$. El trueno retumbó sobre las playas ... 1945. $24.5 \times 34-14$. . . seguido de ecos rotos. 1945. 23 x 33.5.--15. Ahora hity puertos llenos de retorcidos despojos del naufragio. 1945. $33 \times 22.5 .-16 . \ldots$ los bombarderos dejaron su huella de escombros ... 1945. $32 \times 22 .-17 . . . y$ los ejércitos marcharon en loco desorden. 1945. $23.5 \times 34 .-18$. Las ruinas humeantes no brindaban refugio ... 1945. $23 \times$ 33.-19. ...y las mujeres miraban... 1945. $33 \times$ x 22.5.-20. ...los paisajes devastados .. 1945. $22.5 \times 33 .-21$. ...y los hogares despojados de su significado. 1945. $34 \times 23.5$-22. La paz la llegado... 1946. $21 \times 30.5-23 . \ldots y$ el sol proyecta sombras... 1946. 24.5 x 35.-24. ... los pájaros ... 1946. 24 x 34.-25. ... las bestias... 1946. $24.5 \times 39.5 .-26 . \ldots$ los insectos . . 1946. $13.5 \times 19 .-37 . \ldots$ roedores.. 1946. $39 \times 23.5 .-28$. . peces... 1946. $24 \times$ 33.5.-29. . . y s símbolos de otra era. 1946. $41.5 \times 28.5 .-30$. Los hombres hicieron alto, esquivando dar la cara. $1946.32 .5 \times 12.5 \ldots 31 . \ldots y$ las ciudades nuevamente descansan en los valles... 1946. 21.5 x 29.5.-32. ... la tierra una vez mnás recobra su cielo... 1946. $24.5 \times 34.5,-33, \ldots y$ en lontananza las colinas retienen su ritmo. 1946. $32 \times 22 .-34 . \ldots y$ el hombre halla tiempo para nuevos designios. 1946. $41.5 \times 28.5$.-35. Todo termina en un nuevo principia 1946. $32.5 \times 22$. 
Individuales :

36. ... Refugio. 1941. $29 \times 38.5$.-37. Entreacto de vcrano. 1946. $32 \times 21.5-38$. Hay muchas clases de monumcntos. 1947. $24 \times 35$ - 39 . La ausencia de la razón produce monstruos. 1947. $22 \times 33.5$ - 40. Creí haber oído alas. 1948. $32.5 \times 22.5$ 41. A cada quien lo suyo. $1949.39 \times 29$. 42. Burla. 1949. $34.5 \times 24.5 .43 . \mathrm{Y}$, sin embargo, no estaba solo. 1949. $28 \times 40 .-44$. Hombre citadino. 1949. 23.5 $\mathrm{x}$ 34. 45. Rebeldín no es un solo gesto. 1949. $30 \times 45.46$. El tiempo tiene forma. 1950. $28 \times 37.5$.

De la serie hecha en México "Cada hombre en su ticnupo":

47. Del amoroso calor. 1951. $44 \times$ 34.-48. A elevatos horizontales. $1951.43 \times 34.5$. -49. Camina solo. 1951. $43.5 \times 34.5 .-50$. Donde muchos duermen. 1951. 43.5 $\times$ 34.5.-51. O buscan en la oración. 1951. $43.5 \times 34 .-52$. En pos de profetas. 1951. 43.5 x 34.-53. Cruza los océanos. 1951. $43.5 \times$ 34.-54. Prueba la ciudad. 1951. 43.5 $\times$ 34.-55. Arrastra las cargas. 1951. $44 \times 34.5 .-56$. Jaa :nultitud sigue su marcha. 1951, $43.5 \times 34 .-57$. Aprende el significado, 1951, 44 $\mathrm{x}$ 34.5.-58. Y reposa nucvamente en el amor. 1951. $44 \times$ 34.-NOTA: Todas las medidas son en centimetros.

AGOSTO

* Toby Joysmith.-Exposición de pinturas presentada por The Britis Council, en el Instituto Anglo-Mexicano de Relaciones Culturales, Pánuco, 10. Desde el primero de agosto.

Oleos:

1. Bambú en paisaje caliente.-2. Hojas de flátano en paisaje.-3. Palmera.-4. Popocatepetl y formas de cardo, Amanccer.-5. En el jardín.-6. Danzantes.7. Telares I.-8. Telar II.-9. Telar IIl.-10. La Selva, Oaxaca.

Dibujos :

1. Indígena en hierba alta, selva, Oaxaca.-2. Maiz.-3. Mercado de Cuernavaca.4. Figura de espino I.-5. Figura de espino II.-6. Montañas y calle-7. Jacarandas.-8. Nacimiento de un anacoreta.-9. Cuerpo magnético.

* Howard Smith.-Exposiciún de pintura presentada por el Instituto MexicanoNorteamericano de Relaciones Culturales, en Yucatán, 63. Desde el 8 de agosto.

1. My Wife--2. Eric Tyrell Martin-3. Woman in Black-4. Mrs. Leland Cagwin.--5. Tommy.-6. Mid-day, San Miguel Allende.--7. Church of Guadalnge, Cho!nla.-8. Tasco.-9. Sierra Nevada Meadow.-10. Convento de San Francisco, San Miguel Allende.-11. Church of San Francisco, Tasco.-12. Mexican 
Patio.--13. Convento Calvario, Teluacán.-14. Criadas at a Fountain.-15. View of Tasco.-16. Fernanda.-17. The Bee Tree--18. Tee Jay Lake (Sierra Nevada Mountains).-19. Before the Start, Jannaica.-20. White mare and foal.21. Spanish Peasant.-22. Vaquerito.-23. Horses in a Tent.-24. Church of San J11an de Dins, San Miguel Allende.-25. Polo.-26. Boy with Tejocotes.27. Popocatepetl from Puebla.-28. My fancy.-29. Val.-30. Set of Lithographs (Stone).

* Marta Adants.--Exposición de dibujos a tinta, titulada "Portafolio Siciliano", presentada por la Galería de Arte Moderno, Plaza Santos Degollado, 16 C y D. Del 8 al 28 de agosto.

1. Fora Dagao.-2. Castillo del Cíclope.-3. La orilla de Catania.-4. Castillo del Cíclope.-5. Entre montañas.-6. Paquito.-7. Paisaje.-8. Pucblecito sobre PeJregal.-9. En el 'Teatro Griego.-10. Castillo Vescio.--11. Convento de las monjas blancas.-12. La Muerte no muere. (Catacumbas).-13. La Muerte no nuere. (Catacumbas 2),-14. Sra. Flores-15. Paisaje---16. Por la orilla del mar.-17. Taormina.-18. Entre lit Sierra.-19. Olivetti-20. Taormina 2.-21. Calle en Taormina.-22. Cuando los almendros están en flor.-23. Paisaje Jeroico con Monte Etna.-24. Joseppina.

* Carlos R. López--Exposición de pintura presentada por la Galería de Arte Moderno, en la planta baja de su local de Plaza Santos Degollado, 16 C y D. Del 8 al 28 de agosto.

Oleos:

1. Retrato.-2. Máscara.-3. Calavera.--4. La ventana.-5. Cabeza de niña.-6. El Pedregal.-7. Esmeralda 14.-8. Nubes en el Pedregal.-9. Contreras. (La Estación).-10. El niño de la jaula.-11. Tlalpujalnua, Mich.

Gouaches:

12. El Tepeyac-13. Cabeza.-14. La Barranca, Experiencia, Jal,-15. Naturaleza muerta.-16. Caracoles.-17. Clapnltepec.-18. Tabiqueros.-19. Cementerio.

Acuarelas :

20. Sån Fernando.-21. El tronco.-22. Coyoacán.-23. Piedras.-24. Temajac, Jal.

* Desiderio Hernándes Xochitiotain.-Exposición de temas precortesianos, presentada por la Unión de Artes Plásticas y La Peña Amigos del Arte, en la Sala Agustin Arrieta y el Estudio del Artista, en la ciudad de Puebla, Pue. Del 9 al 30 re agosto.

1. Miquiztli. Muerte.-2. Apanoayan. En el Valle del Río con el perro Techichi.-3. Tepeme Monamictia. Las Montañas cjue clocan.--4. Itztepetl. El Cerro de las 
Puntas de Obsidiana.-5. Celnuecayan. En los Collados donde liela.-6. Itzehecayan. Donde el viento es de Obsidiana.-7. Teocelolualoyan. E1 Tigre que se come al corazón.-8. Apanhuiayo. En el agua negra con la lagartija Xochitonal.-9. Chiconauhapan. En las Nueve Corrientes.-10. Mictlan. Donde nueren los muertos.-11. Teoyahuitl. El dador azul.-12. Tlaloc-Teopixccelotl-Tlapaltlahcuilohc. Deidad de la Lluvia-Sacerdote Tigre Pintor.-13. Metl uan Amatl-Amacapanalli-Amoxtle. Papel de Maguey y Amate-Estola de Papel Códice--14. Nopalli. Nopales.-15. Quiyotl. Quiote-16. Ehecatl. Viento. Adrocación de Quetzalcoatl.-17. Miquiztlxochicuepone. Muerte florida-18. Quetzalcóatl. Serpiente emplumada. Cabeza de la Deidad.-19. Tlaloc. Deidad de lä Lluvia.-20. Yochtli. Conejo.-21. Hueluteteotl. Dios viejo.-22. Macuilxochitl. Deidad de las flores,-23. Coatl. Serpiente-24. Cemilicaccoatl. Serpiente de la Eternidad.-25. Teotetlacaquitiliz. Reunión de Dioses,--26. Tlacatiliztl-Metzintli. Nacimiento de 1a Luna.-27. Tlacatiliztl-Tonaltzin. Nacimiento del Sol.-28. Quetzalcóatl. Deidad Cultural.-29. Coatlicue. Diosa de la Tierra.-30. Huitzilopochtli. Deidad de la Guerra.

* Ignacio Aguirre--Exposición de pintura presentada por el Salón de la Plástica Mexicana, Galería de Ventas Libres, del Instituto Nacional de Bellas Artes. Del 25 de agosto al 19 de sentiembre.

1. Cabeza de Mujer. Oleo. 1943.-2. Autorretrato. Oleo. 1945.-3. Composición. Oleo. 1946.-4. Mujer sentada. Oleo. 1946.-5. Maguey. Oleo al temple. 1948.-6. Niñas. Oleo. 1948.-7. Trabajadores. Encáustica. 1948. -8. Niñas en blanco. Oleo. 1949. Col. Sr. Ing. Federico Peña Aguirre--9. Paisaje. Oleo. 1949.-10. Niña Tarasca. Oleo al temple. 1950.-11. Muclacha Tarasca. Oleo al temple. Col. Sr. Francisco S. Iturbe.-12 Cabaretera. Oleo. 1950.-13. Huelga. Oleo al tenple. 1951.-14. Ofrenda. Oleo al temple. 1952.-15. Las Marchantas. Oleo a! temple. 1952.-16. Las Hilanderas. Oleo al temple. 1952,-17. Mujeres Tarascas. Oleo. 1952 .

Temples:

1. En la Cola de Carbón. 1947.-2. Paisaje. 1947.-3. Paisaje. 1947.-4. Paisaje de Rocas. 1948. Col. Sr. Ing. Federico Peña Aguirre-5. En el Tren. 1948.

* Sociedad Mexicana de Grabadores.-Exposición de grabado a color, presentada por la Galería Artística Olivetti $y$ la Galería de Atte Moderno, en Giadalajara, Jal, calle de López Cotilla, 389. Durante el mes de agosto.

Lote retrospectivo:

Jean Charlot: 1. Carátula del libro "Urbe". 1924. Madera de hilo.-Francisco Díaz de León: 2. Ilustración al libro Taxco. 1926. Madera de pie.-3. El Ajusco. 1930. Aguatinta-Tamiji Kitagazea: 4. Paisaje de Tlalpan. 1927. Madera de hilo.-Feliciano Peña: 5. Escena Doméstica. 1930. Aguatinta.--Isidoro Ocam- 
po: 6. Juguete popular. 1931. Madera de hilo.-Margarito N.: 7. Juego Infantil. 1936. Camafeo.-Emilio Amero: 8. Cabeza de mujer. 1938. Litografía.

Lote contemporáneo:

Celia Calderón: 9. Cabeza de mujer. Litografía.-10. Maternidad. Aguafuerte.Suzanne Daco: 11. Hacienda de Bélgica. Madera de hilo.-Angeles Garduño: 12. Mambo callejero. Aguafuerte-13. Novia pueblerina. Aguafuerte-Edelmira Losilla: 14. Lavanderas. Barniz suave.-15. Mujer en el jardín. Aguafuerte-Luis Beltrán: 16. Horno de tabique. Linóleo.-17. Figura. Linóleo--Pedro Castelar: 18. Hoguera. Aguatinta.-Jean Charlot: 19. Primeros Pasos. Litografía. -Francisco Díaz de León: 20. Amigos. Madera.-21. Viajeros. Madera.Manuel Echauri: 22. Desnudos en el campo. Aguatinta.-23. Niños. Buril.-G. Fernández Ledesma: 24. Homenaje a Cuauhtémoc. Linóleo--Raúl Gamboa: 25. Baño junto al pozo. Linóleo.-A. Guati Rojo: 26. El Hombre Azul. Aguatinta. -27. Coloquio de Jueguetes. Aguatinta.-M. Herrera Cartalla: 28. Vendedora de Alfalfa. Aguatinta.-29. Los Judas. Aguatinta.-Amador Lugo: 30. Paisaje. Linóleo.-31. Canastas. Linóleo.-Ernesto Ornelas: 32. Paisaje. Aguatinta.-33. Mendigo. Aguatinta.-Feliciano Peña: 34. El Columpio. Aguatinta.-35. Paisaje de Tepoztlán. Linóleo.-José J. Rodríguez: 36. Naturaleza muerta. Linóleo. -37.Calle de Querétaro. Linóleo._Francisco Salmerón: 38. Expolio. Linóleo.Paulina Trejo: 39. Señor de la Caña. Linóleo.-40. Juguetes de Corpus. Linóleo.-Francisco Vázquez: 41. Arboles. Aguatinta.42. Calle con árboles. Aguatinta.-Angel Zamarripa: 43. Mulata. Aguatinta.44. Angela Peralta. Linóleo.

\section{SEPTIEMBRE}

* Instituto Nacional de Antropología e Historia.-Exposición del Material Arqueológico descubierto en la Cámara Secreta de Palenque, Chis., en el Museo Nacional de Antropología, Moneda 13. Desde el 3 de septiembre.

* Antonio Román Hernández.-Exposición de grabado titulada "Posadas Poblanas", presentada por la Unión de Artes Plásticas y la Peña Amigos del Arte de la ciudad de Puebla, en la planta baja de la Galería de Arte Moderno, de la ciudad de México, Plaza Santos Degollado, $16 \mathrm{C}$ y D. Desde el 5 de septiembre.

* Galería Arte Moderno.-Exposición de Pintura Mexicana Contemporánea, Sala de Arte Mexicano, presentada en la planta alta de su local de Plaza Santos Degollado, 16 C y D. Desde el 5 de septiembre.

* Galeria Arte Moderno.-Exposición de grabado de la Escuela Francesa, Salón de Arte Francés, presentada en la planta alta de su local de plaza Santos Degollado, $16 \mathrm{C}$ y D. Desde el 5 de septiembre.

* Instituto Nacional de Bellas Artes.-Exposición de Grabado Mexicano Contemporáneo, presentada en la Sala Verde del Museo Nacional de Artes Plásticas, Palacio de Bellas Artes. Desde el 25 de septienbre. 
* Héctor Xavier y Vlady.-Exposición de pintura presentada por la Galería Prisse, Londres, 163. Desde el 26 de septiembre.

* Nicolás Moreno.-Exposición de pintura y grabado presentada por el Salón de la Plástica Mexicana, Galería de Ventas Libres del Instituto Nacional de Bellas Artes. Desde el 29 de septiembre al 25 de octubre.

1. Minas de Tezontle. Oleo sobre masonite. 1950.--2. La Sávila y los Adobes. Oleo sobre masonite. 1951--3. El Pedregal desde el Zacatepec. Oleo sobre triplay. 1951.-4. El Camino Real. Olco sobre masonite. 1951.-5. Tezontle. Oleo sobre masonite. 1952.-6. Tezontle. Oleo sobre masonite. 1952.-7. La Semilla. Oleo sobre masonite. 1952.-8. El Letrero Amarillo. Oleo sobre masonite. 1952.-9. El Valle desde la Loma. Oleo sobre masonite. 1952.-10. La Aparición de las Encinas. Oleo sobre masonite. 1952.-11. La Peña. Oleo sobre masonite. 1952.12. El Globo. Oleo sobre masonite. 1952.-13. El Enfermo. Oleo y temple sobre masonite. 1952.-14. Una limosnita. Oleo y temple sobre papel. 1952.

Grabados:

1. E1 Mercado de Juchitán. Grabado a buril. 1952,-2. Maternidad. Grabado a buril. 1952.-3. Al mercado. Grabado a buril. 1952.-4. Madre Mestiza. Grabado a buril. 1952.-5. La Espera. Grahado a buril. 1952.-6. Niños Juclitecos. Grabado en linóleum. 1952.-7. El Borraclito. Grabado a buril. 1952.-8. La Mona. Grabatlo a burit. 1952 .

\section{OCTUBRE}

* Emma Réyes.-Exposición de pintura presentada por la Galería de Arte Contemporáneo, en sus salones de Amberes 12. Del 2 al 18 de octubre.

* Mamel Alvares Bravo.-Exposición de fotografias presentada por The Britisl Council, en el Instituto Anglo-Mexicano de Relaciones Culturales, Pánuco, 10. Del 3 al 13 de octubre.

* Allan Cash.-Exposición de fotografías presentada por The British Council, en el Instituto Anglo-Mexicano de Relaciones Culturales, Pánuco, 10. Del 3 al 13 de octubre.

* Geles Cabrera.-Exposición de esculturas presentida por la Galería de Arte Moderno, en su local de Plaza Santos Degollado, 16 C y D. Del 10 a] 31 de octubre.

1. Figura masculina. Piedra negra.-2. Desnudo. Piedra chiluca.-3. Pareja. Piedra chiluca.-4. Desnudo sentado. Bronce-5. Indígena. Bajorrclieve. Piedra américa--6. Chet---Bajorrelieve. T'iedra anérica-7. Sirena. Estaño. 
* Valetta Swann.-Exposición de dibujos presentada por The British Council, en el Instittuo Anglo-Mexicano de Relaciones Culturales, Pánuco, 10. Del 14 al 31 de octubre.

1. Mariquita. Carbón y pastel.-2. Fisonomías. Sanguinea negra con tinta.-3. Venta de Maíz. Dibujo al óleo.-4. Melchor. Sanguinea.-5. Triste y pensativa. Sanguínea negra.-6. Real del Monte. Tinta con pluma de feltre-7. Peña dc1 Cucrvo. Carbón.-8. Julia. Sanguínea.-9. Resoluta. Sanguínea.-10. Istmeña. Pastel.-11. Juanita. Carbón.-12. La Danza. Tinta con pincel chino.-13. La Siembra. Tinta con pincel clino.-14. Procesión. Pastel con tinta.-15. Pose. Carbón.-16. En Río-Mar. Sanguínea.-17. Difuntos. Tinta con pincel chino.18. Funeral juchiteco. Carbón.-19. Lá Purísima. Carbón.-20. Desnudo. Carbón y pastel.-21. Desde el Cerrito. Carbón.-22. Las Hermanitas. Tinta con óleo.23. En 10 mo al Ajusco. Carbón.-24. Las Calderas. Carbón.-25. Las Siete Sabias. Sanguínea negra.-26. Música de Feria. Tinta china-27. Bailando. Tinta con pincel chino.-28. Indio Chamtula. Carbón.-29. La Chistosa. Pastel.30. La Negrita. Sanguínea.-31. La Lavandera. Sanguninea.-32. E1 Volantin. Tinta Clina.-33. El Tigre. Carbón.-34. El Sacristán. Sangúnea negra.-35. Mujer tztzil. Carbón.--36. Lago de Texcoco. Tinta con pluma de feltre.--37. Ja Esfinge: Sanguínea negra.-38. Aguilucha. Sanguínea nogra con tinta.-39. Esturlios de desnudo en sanguínea.--40. Apuntes del circo en sanguínea negra.

* Armando García Núnez-Exposición de pinturas presentada en lis Galerías de la Librería Juárez, Avenida Juárez, 102. Del 15 al 31 de octubre.

1. Montañas de Arizona.-2. La tormental. Lomas de Mixcoac.-3. La lluvia. Lonas de Mixcoac.4. Sierra de Guerrero. Anmecer.-5. En la Sierra. Edo. de Morelos. 6. Entrada al ex Convento de Churubusco.-7. Marina Acapulco. Icacos.-8. Montañas de Arizona. Nuevo México.--9. Montañas de Arizona. Nuevo México,--10. Marina. Acapulco.-11. Lomas de Mixcoac-12. Crepuisculo. El Pedregal.--13. Crepúsculo. El Pedregal.--14. Presa de Tarango.15. La Colegiala.-16. Mujer cosiendo.-17. Soledad.-18. Gitanas en mi estudio.-19. Gitanas en mi estudio.-20. Naturaleza muerta.-21. Camino a Cuernavaca.--22. Rincón de mi casa.-23. Camino a Cnernavaca--24. Estudio de Rocas. Villa de Guadilupe--25. Estudio de Rocas. Villa de Guadalıpe-26. Crepúsculo.-27. Lomas Mixcoac.-28. Lavandera.-29. Cabeza de Estudio.-30. Molino de Rosas. Mixcoac.-31. Chalco. Estado de México.-32. El Pastor.-33. Minas del Cristo. Mixcoac.-34. La Agnadora.-35. Crepúsculo-36. Estudio de árboles. Mixcoac.--37. Atardecer. Mixcoac.-38. Casitas de Isleta. El Paso Texas,-39. Canino a Cuenavaca.-40. Nevada Santa Fe. Nuevo México-41. Camino a Tarango. Mfixcoac.-42. Atardecer. E1 Paso Texas.-43. Montañas de Arizona.-44. El 1xtaccíluatl.-45. Puesta de Sol. Olivar del Conde.-46. Montañas de Albuquerque. Nucvo México.-47. Río de Mixcoac.48. Tarango. Mixcoac-49. Canino a Tarango. Mixcoac.--50. Antes de la 11nvia. Mixcoac.-51. Iglesia de Tryelntalco,-52. Río Grande. U. S. A.--53. Escenas de Ballet.-54. Escenas de Ballet.-55. El descanso. 
DOI: http://dx.doi.org/10.22201/iie.18703062e.1953.sup1.2455

Dibujos :

56. Estudio de Desnudo.-57. Apuntes.-58. Estudio de Desnudo.-59. Estudio de Desnudo. -60. Apuntes de Desnudo.

* Leonardo da Vinci-Exposición ambulante de reproducciones, preparada por la UNESCO y presentada por el Instituto Nacional de Bellas Artes, en la Sala de la Estampa del Museo Nacional de Artes Plásticas, Palacio de Bellas Artes. Desde el 17 de octubre.

* Enrique Climent-Exposición de pinturas presentada por la Galería de Arte Mexicano, en su local de las calles de Milán, 18. Del 17 de octubre al 10 de noviembre.

Oleos :

1. Naturaleza muerta.-2. Formas volantes.-3. El juego.-4. La carabela fantástica. -5. Interior en Damásco. -6. Crepúsculo en el corral.-7. Figuras paralelas.8. Juego de líneas. -9. Mascarada en el desierto.-10. E1 retorno.-11. Anunciación I.-12. Danza ritual-13. Trío en la noclee.-14. Inego de formas.-15. Armonía en ocres.-16. Eclipse de siete limas.

Gourches :

17. Naturaleza muerta.-18. Formas tropicales.-19. Feria en Arabia.-20. Frutas.

Viñelitas:

21. Pájaro sulmarino,-22, Contraluz._23. Espina.-24. Anunciación II.

Ceras:

25. Violinista,-26. Flautista,--27. Composición,-28. Fignra arcaica.-29. Formas en el espacio.-30. Cristo chino.-31. Calle bajo la lına.-32. El gong.-33. El pájaro de fuego.-34. Planta marina.-35. El pájaro alerta.-36. Máscara negra. -37. Llamadia al sacrificio.

Lápices de colores:

38. Armonía turca.-39. Pantomina negra-40. Figura alucinada.-41. Máscara con antenas.-42. Procesión de viernes sunto-43. Maternidad.-44. Pax mosaico.

Monotipos :

45. Serenata.-46 a 55 . 
Dibujos:

56. Cazador de mariposas.

* Secretaría de Recursos Hidráulicos y el Frente Nacional de Artes Plásticas.-Exposición concurso de grabado, interpretando el programa de la Secretaría de Recursos Hidráulicos en el Sexenio 1947-1952, presentada en la Sala de Bellas Artes del Palacio de Bellas Artes. Del 17 de octubre al 5 de Noviembre.

Concursantes:

Alba Ibarra, Gregorio: 1. Conquistando el desierto. $31 \times 47 .-4$ lvarado Lang, Carlos: 2. La Conquista del agua. Aguafucrte. $40 \times 29.5-3$. Agua $\sin$ fronteras. $64 x$ 66.-Anomiano, Raill: 4. El agua y la tierra dura. Litografía. $42 \times 50$-- 4 zila Pcralta, Carlos: 5. Grabado sin título. $40 \times 30-4$. Rosa: 6. Grabado sin título. $40 \times 30$--Arcllano Torres, Agustin: 7. Agua. vida para México. $49 \times 58$ Alarare Anaya Jesuis: 8. Tláloc sobre México. 50 x 59.5 -Baltasar $R$., Roberto: 9. Sueño del Campesino. $56 \times 45 .-B e l t r a ́ n$, Iuis: 10. Grabado sin título. 47 x 64.-Bracho, Angel: 11. Grabado sin título, a color. $60 \times 50$-Casillas, Gustazo: 12. Grabado sin título. $42 \times 30$-Castillo Alvarez, Carlos: 13. Sequía. $34.5 \times 43$-Cattlet, Elizabeth: 14. Presas y electrificación. $40 \times 30$-Cortés Juárez, Erasto: 15. La Irrigación enriquece la producción agrícola. $39.5 \times 30$.Dosamantes, Francisco: 16. Sequía. $56.5 \times 39.5$-17. Irrigación-Industria. $73 \times$

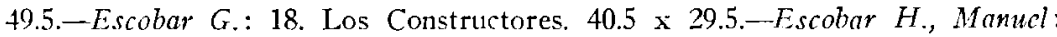
19. Grabado sin título. $40 \times 29.5$.-Escobedo, Iesus: 20. I.jtografía sin título. $51 \times 40$-Estrada Hernández, Arturo: 21. Grabado sin títuolo. $45 \mathrm{x}$ 45.-García Maldonado, Alberto: 22. Grabado $\sin$ título. $40 \times 30$-Gonsálcz, Guillermo: 23. El Mito del Agua. $1.76 \times 75$.- Herrera Cartalla, Manuel: 24. 1952 : México en marcha. $30 \times 39.5$-Larios: 25. Germinación. $65 \times 53.5$ Lazzaroni, Dante: 26. El Agıa presa. $30.5 \times 37.5$--Ranón Pablo, Lorcto: 27. La tierra responde. 43 x 30.-Losilla Aguilar, Edelmira: 28. 1947-1952. 57 x 42.-Lugo, Amador: 29. Grabado sin título. $29.5 \times 39.5 .-30$. Grabado sin título. $39 \times 50 .-31$. Grabado sin título. $30 \times 40$ - Marquina, Angel: 32. Grabado sin título. $43 \times 30$.-Martines, Arteche: 33. Quetzalcoatl tiene sed. $40 \times 29.5$ Mendarozqueta, José: 34. Grabado sin título. $32 \times 40$-Mcxiac, Adolfo: 35. Productos del riego. $35 \times 45$-36. Grabado sin título. $37 \times 53.5-$ Mora, Francisco: 37. Ia Presa Falcón. 55 x 45.-Morales Aguilar, Francisco: 38. La técnica lidráulica, elemento de progreso. 44 x 32.-Paredes, Mariano: 39. Grahado sin título, $57.5 \times 80$.-Paz Pérez, Gonzalo de la: 40. Grabado sin título. $40 \times$ 49.5.-Pumphrey, Bert: 41. E1 futuro del Papaloapan. 40.5 x 30.-42. "Atl". 29.5 × 30.5.-Rabel, Fanny" 43. La Sequía. 38 x 29.5.-Ramírez, Everardo: 44. Grabado sin título. $35 \times$ 40.-Ramires Osorio, Fenando: 45. Grabado $\sin$ título. $30.5 \times 40 .-$ Rincón Piña, A.: 46. Agua fuerte sin título. $40 \times$ 30.-Salmerón, Francisco: 47.La irrigación coronamiento de la Conquista de la tierra. 54 x 42.5.- Salazar, Gustazo: 48. Grabado sin título. $30 \times 40.5$. - Tenorio B., Eliseo: 49. Fecundaciom. $40 \times 40$ - Torres, Esteban: 50. Grabado sin 
título. $30 \times 40 .-$ Trejo, Paulino: 51. Grabado sin título. $30 \times 40.5,-52$. El Riego. 37.5 x 50.-Yampolsky, Mariana: 53. Llegó la vida. 44.5 x 55.-NOTA: Todas las medidas son en centímetros.

* Antonio Pcláez--Exposición de pintura y dibujo, presentada por la Galería de Arte Conteinporáneo en sus salones de Amberes, 12. Del 23 de octubre al 8 de noviembre.

Pinturas :

1. Autorretrato,-2. Guillermo Terminel.-3. Carmen.-4. Emilia Venero.-5. Roberto Garza.-6. Homenaje a Liborjo.-7. Rocas.-8. Domingo en Candela.9. Tiempo.-10. El Espejo.--11. Paisaje.-12. El Recuerdo.-13... Zarina.14. Presencia.-15. Mujer azul.

Dibujos :

1. Lupe Marín.-2. Oralia Donínguez.-3. Lol: Alvarez Bravo.-4. Frida.-5. Nieves Orozco.-6. Guadalupe Amor.-7. Carmen Sordo.8. Ruth Rivera.-9. Olga Campos.-10. Anelia Abascal--11. Francisco Tario.-12. Sergio Pelúez.13. Julio Peláez.

* Instituto Nacional de la Inéntud Mericana--Exposición concurso de dibujo, srabado, pintura y escultura, presentada en la Galería José Clemente Orozco, del Instituto Nacional de Bellas Artes. Durante octubre.

Concursantes:

Alvare del Castillo, Scrgio. 17 iños: 1. Norma. Escultura en yeso.-Arechiga Tiramontes, Refugio. 20 anios. 2. Figura caminando. Escultura en yeso.-Arriaga Rico, Antonio, 18 años: 3. El mendigo. Sin fecla. Duco sobre papel. $96 \times 63$ Azila Peralta, Carlos. 21 años: 4. Natumaleza muerta. Sin fecln. Oleo sobre cartón. 63 x 46.-Ayala Gusmán, Héctor. 19 años: 5. Después de la batalla. 1949. Oleo sobre tela $79 \times 99$-6. Mujeres de Yucatán. Sin fecha. Oleo sobre tela. $90 \times 125 .-7$. Independencia. Sin fecha. Piroxilina sobre masonite. $122 \times$ 100.-Becerril Lópes, Francisco. 20 años: 8. Utensilios de fundición. 1950. Telnple sobre papel. $67 \times 93 .-9$. Apunte de noche. 1950. Gouache. $23 \times 16 .-C a-$ rrcón Zamora, Enrique. 19 años: 10. Iglesia de Santa Inés. Sin fecha. Oleo sobre tela. $65 \times 90 .-11$. Paisaje del bosque. Sin fecha. $60 \times 45 .-12$. Retrato de hombre. Sin fecha. Oleo sobre masonite. $40 \times 30 .-13$. Naturaleza muerta. Sin fecha. Oleo sobre tela. 47 x 70.-Casillas Mata, Gustavo. 20 años: 14. Iuguetes de Corpus. Sin fecha. Oleo sobre tela. 50 × 40.-Castillo Rico, Pablo. 18 años: 15. Estudio. Sin Eecha. Oleo sobre tela. 43 x 30.-Castro Haces, Héctor. 17 años. 16. Paisaje. 1952. Oleo sobre tela. $65 \times$ 49. Chávez Cabrales, Humberto. 17 años: 17. La ofrenda. 1952 . Oleo sobre tela. 60 × 50--Cobo Reyes, Raimu- 
do. 18 años: 18. Barro. Sin fecha. Oleo sobre tela. $46 \times 62$.-Coronel Arroyo, Rafael. 19 años: 19. Retrato de mujer. Sin fecha. Duco sobre papel. $80 \times 69$ Cortés, Donato Juan José. 18 años: 20. Santo en oración. Sin fecha. Dibujo al carbón. $47 \times$ 35.-Cuevas Lópes, Germán. 19 años. 21. Pico nevado. Sin fecha. Acuarcla. $32 \times 37 .-22$. Calle de pueblo. Sin fecha. Dibujo a tinta. $19 \times 27$. De la Fuente, Salvador. 20 años: 23. San Angel. 1950. Oleo sobre cartón. $36 \mathrm{x}$ 26.-24. Patos. 1950. Oleo sobre cartón, $26 \times 36 .-$ De la Torre Callejo, Carlos. 15 años: 25. Mujer mongoloide. Escultura en plastilina.-De Vivanco Ires, Alfonso. 18 años: 26. Cabeza de hombre. Escultura en yeso-27. Cabeza de hombre. Escultura en yeso.-28. Cabeza le viejo. Escultura en yeso.-Diaz Esqueda, Jesís. 20 años: 29. Naturaleza muerta. Sin fechí. Oleo sobre iela. 56 × 70.--30. Naturaleza muerta. Sin fecha. Oleo sobre tela. 55 × 70 - Donia Ochoa, Roberto. 18 años: 31. Autorretrato. 1951. Oleo sobre tela. $47 \times 38 .-$ 32. Hombre sentado. Sin fecha. Oleo solbe tela. 65 x 50.-Escatera Romero, Jesús. 19 años: 33. Catedral de Morelia. 1951. Dibujo a lápiz. $92 \times 62 .-34$. Adolescente. 1951. Dibujo a lápiz. 92 x 62.-35. Mercado. 1952. Duco sobre papel. 72 × 97.-36. Figura en descanso. 1952. Litografía. 31 x 24.-37. Puentecito. 1952. Litografía. $52 \times 40 .-38$. Ofrenda. Sin fecha. Temple sobre pape!. 71 x 85.-Estrada Orozco, José Antonio. 18 años: 39. Desuludo. Escultura en plastilina.-40. Muzmé. Escultura en plastilina-Fuentes de la Garra, Crus Mario. 18 años: 41. Estación de ferrocarril. Sin fecha. Oleo sobre tela. $60 \mathrm{x}$ 80.-Galicia Duarte, Benjamin. 19 años: 42. Naturaleza muerta. Sin fecha. Oleo sobre cartón. $28 \times 23 .-43$. El arroyo. Sin fecha. Dibujo a tinta. $23 \times 33 .-$ Gáloes Morales, Fernando. 21 años: 44. India. Escultura en madera-Gonzáles Gaiván, Manuel 18 años: 45. La másearál 1952. Olco sobre teia. 52 x 40.46. Panorámica. 1952. Oleo sobre tela. $38 \times 52$.47. La Piedad. 1952. Dibujo at tinta. $21 \times 29 .-48$. El martirio. Sin fecha. Oleo sobre tela. 41 × 52.-Gon 1 álca Iñignes, Xivier. 19 anos: 49. Retrato de mujer. 1952. Oleo sobre tela. $80 x$ 66.-50. Naturaleza muerta. 1952. Oleo sobre tela. 40 x 51.--51. Naturaleza muerta. 1952. Dibujo a lápiz. 33 x 45.-Gonzálea Ponce, Celia. 21 años: 52 Paisaje. 1949. Grabado. 17 × 16.-53. Pórtico. 1952. Grabado. 28 × 21.-54. Calle de pueblo. 1952. Acuarela. 24 x 34.-Gonzáles Pozo, Alberto. 19 años: 55. Estudio. 1952. Oleo sobre masonite. 60 x 48.-56. La Ofrenda de la Raza. 1952. Acuarela sobre hule. 25 x 20.-Gómes García, Héctor. 20 años: 57 . Soledad. 1952. Dibujo al carbón. 25 x 20.-58. Tranquilidad. 1952. Dibujo al carbón. $24 \mathrm{x}$ 31.-59. Necesidad y fuerza. 1952. Dibujo al carbón. $38 \times 51$--Heredia Martimes, Filiberto. 20 años: 60. Naturaleza muerta. Sin fecha. Oleo sobre iela. $64 \times 75$-61. Cazahuatl. Sin fecha. Oleo sobre tela. $75 \times 66$-Hemándes Alzarez, Raúl. 20 años: 62. Mujeres. Sin fecha. Oleo sobre madera. $34 \times 46 .-$ Hernándes España, Fernando. 19 años: 63. Tasco de noche. Sin fecha. Oleo sobre cartón. 26 x 36.-Hernández Espinosa, José. 20 años: 64. Naturaleza muerta. Sin fecha. Oleo sobre cristal. $27 \times 35$.-Herrera Arroyo, Telcsforo. 21 años: 65. Pescadores. 1952. Oleo sobre tela. 70 x 90.-66. Panorámica. Sin feclia. Oleo sobre tela. $80 \times 120$-Laisequilla Senties, Manuel. 18 años: 67. Cuaulitémoc. 1952. Oleo sobre cartón. $61 \times 46 .-68$. Retrato de hombre 1952. Oleo sobre cartón. $65 \times 45 .-69$. Estudio. 1952. Oleo sobre masonite. $63 \times 43$. 
Laylzon Gómes, Rodolfo. 20 años: 70. El inofensivo. 1952. Dibujo a tinta. $25 x$ 33.-Lima l'clázques, Gabricl. 21 años: 71. Autorretrato. Sin fecha. Oleo sobre masonite. $76 \times$ 62.-Lira Rodríguez, José Luis. 20 años: 72. Velorio. Sin fecha. Pastel. $46 \times 62 .-73$. Nocturno. Sin fecha. Pastel. $48 \times 45$-López Anduaga, Rodolfo. 18 años: 74. Cadenas de la Colonia. Sin fecha. Oleo sobre tela. $61 x$ 46.-López Lópcs, Rubén. 19 años: 75. Paisaje del Chico. Sin fecha. Oleo sobre cartón. $45 \times 56 .-76$. Estampa de Corot. Sin fecha. Oleo sobre tela. $41 \times 50$. 77. Estampa china. Sin fecha, Pastel. $47 \times 40$-L Loya Urquizo, Alfredo. 19 años: 78. Paisajc. Sin feclia. Oleo sobre masonite. $49 \times 41$--Martines Arteche, Héctor. 17 años: 79. La ida. Sin fecha. Piroxilina sobre tela. $72 \times 98 .-$ Martínes Arila, Francisco. 20 años: 80. Raza y barro. Sin fecha. Oleo sobre tela. $57 \mathrm{x}$ 64.-Martines García, Virgilio. 18 años. 81. Naturaleza muerta. 1952. Oleo sobre tela. $44 \times 61$.- Mendoza Blanco, Jorge. 17 años: 82. Naturaleza muerta. Sin fecha. Oleo sobre cartón. $59 \times 46 .-83$. Calabazas. Sin fecha. Oleo sobre cartón $63 \times$ 45.--Montemayor Estrada, Rolando. 14 años: 84. Tasco. Sin fecha. Oleo sobre tela. $44 \times$ 33.-Morales Sordo, Nan. 17 años: 85. Escnltura en mármol.-Orozco Guzmán, Artemio. 19 años: 86. Naturaleza muerta. Sin fecha. Oleo sobre tela. $40 \times 60 .-87$. Paisaje. Sin fecha. Oleo sobre tela. $50 \times 70 .-$ Plata Madin, Agustin. 19 años: 88. Retrato de hombre. Sin fecha. Pastel. $56 \times$ 47.--Ramos Salinas, Victor Manuel. 16 años: 89. Soldaderas. Sin fecha. Acuarela. $36 \times 28$.-Hernán Obregón, Rubén. 20 años: 90. Danzantes. Sin fecha. Oleo sobre tela. 66 × 91.-Rivera, Blanca Lus. 17 años: 91. Rinconcito. Sin fecha. Dibujo a tinta. $25 \times 33$.- Rodrigues Silva. Victor Manuel. 16 años: 92. Retrato de hombre. 1952. Oleo sobre masonite. $29 \times 36 .-$ Rosas Dia $\approx$, Iulia Alicia. 16 años: 93. Animales marinos. Sin fecha. Pastel. 51 x 66.- Sánche Centcno, Julio César. 17 años: 94. Vendedora. Sin fecha. Grabado. $20 \times 24 .-95$. Naturaleza muerta. Sin fecha. Oleo sobre cartón. $30 \times 48 .-$ Sánchez Vázquez, Socorro. 21 años: 96. Laguna de Cuyuca. Sin fecha. Acuarela. $21 \times 27 .-97$. Peregrinación. Sin fecha. Pastel. $50 \times 60$.-Santiago Vázquez, Beatriz. 17 años: 98. Patio de Vecindad. Sin fecha. Oleo sobre cartón. 40 x 30.-Suro Olivares, Jocl. 20 años: 99. Naturaleza muerta. Sin fecha. Oleo sobre tela. 46 x 61.Yelasco Lcón, Agustín. 19 años: 100. Naturaleza muerta. 1951. Oleo sobre tela. $62 \times 44 .-101$. Naturaleza muerta. Sin fecha. Oleo sobre tela. $60 \times 70 .-102$. I izuet Garcia, Ada. 15 años: 102. Judas. Sin fecha. Oleo sobre tela. $49 \times 39$.-Yánca, Alicia. 17 años: 103. Choza. Sin fecha. Dibujo a tinta. $25 \times 33$. Yánez Loeb, Antonio. 18 años: 104. Perros, 1949. Oleo sobre tela. 50 x 66.-Zúniga Araiza, Arturo. 19 años: 105. Estudio. Sin feclua. Dibujo al carbón. 37 x 27.

Obras premiadas:

Arriaga Rico, Antonio. 18 años: 1. Vista Panorámica. Sin fecha. Oleo sobre madera. $60 \times 80$-Beccrril Lópes, Francisco. 20 años: 2. La calavera. 1947. Oleo sobre tela. $45 \times 60$.-Casillas Mata, Gustavo. 20 años: 3. La espera. Sin fecha. Agua resina. $24 \times 16$-4. Cabeza. Sin fecha. Agua resina. $16 \times 11 .-5$. Paisaje. Sin fecha. Litografía. Camafeo. $30 \times 44.6$. Niño sentado. Sin fecha. Grabado en linóleum. $15 \times$ 9.-Carreón Zamora, Enrique. 19 años: 7. Naturaleza muerta. 
1950. Oleo sobre tela. 50 x 60.-Coronel Arroyo, Rafacl. 19 años: 8. Mujer de Jérez. Sin fecha. Cera sobre cartón. 55 x 54,-De la Torre Callejo, Carlos. 15 años: 9. Autorretrato. Escultura en plastilina.-Doniz Ochoa, Roberto. 18 años: 10. Retrato. 1951. Oleo sobre tela. 65 x 50.-Escalera Romero, Jesús. 19 años: 11. Paisaje. Sin fecha. Oleo sobre madera. $60 \times 80$.-Fuentes de la Garaa, Cruz Mario. 18 años: 12. Cabeza de mujer. Sin feclat. Dibujo a tinta. 54 × 36.- Galicia Duarte, Benjamín. 19 años: 13. Paisaje. Sin fecha. Oleo sobre triplay. 20 x 37.-Gálvez Morales, Fernando. 21 años: 14. Cabeza de mujer. Escultura en madera.-González Iñiguez, Xavier. 19 años: 15. Autorretrato. Sin fecha. Oleo sobre tela. $30 \times 25 .-G o n z a ́ l e z ~ G a l v a ́ n$, Mamuel. 18 años: 16. Acueducto gris. Sin fecha. Oleo sobre tela. 50 x 35.-González Pozo, Alberto. 17 años: 17. Ansiedad. 1952. Oleo sobre hule. 25 x 20.-Hernández Barragán, Augusto. 16 años: 18. Xochimilco. Sin fecha. Oleo sobre madera. $31 \times 42$.-Herrera Arroyo, Telésforo. 21 años: 19. Yolanda. 1951. Oleo sobrc tela. $65 \times 55 .-H u e r t a$ Calderón, Antonio. 17 años: 20. Playa de Hornos. Sin fecha. Dibujo a lápiz. $57 \mathrm{x}$ 72.-Laisequilla Senties, Manel. 18 años: 21. Autor retrato. Oleo sobre cartón. 65 x 46.-Martinez Arteche, Héctor. 17 años: 22. Desnudo. 1952. Oleo sobre tela. 102 x 76.-Romero Alvarado, Carlos. 18 años: 23. Las máscaras. 1952. Oleo sobre madera. $41 \times 51$.

Obras seleccionadas:

Avila Peralta, Carlos. 21 años: 1. Naturaleza muerta. Sin fecha. Oleo sobre cartón. $45 \times$ 63.-Ayala Guzmán, Héctor. 19 años: 2. Desnudo. 1952. Oleo sobre tela. $102 \times$ 69.-Carbajal Jordán, Antonio. 19 años: 3. Tlacotalpan. Sin fecha. Oleo sobre masonite. 40 x 60.-Carransa Cervantes, María Elena. 21 años: 4. Alcatraces. Sin fecha. Oleo sobre tela. 56 × 40.-Castillo Alvarez, Carlos. 17 años: 5. Retrato. 1951. Dibujo a tinta. 55 x 37.-Chacón Miranda, Xavier. 20 años: 6. Estudio. Sin fecha. Pastel. 50 x 38.-Cházez Vega, Guillermo. 21 años: 7. Retrato de niña. 1952. Oleo sobre tela. $69 \times 49$.-De Vivanco Fres, Alfonso 18 años: 8. Cabeza. Escultura en yeso.-Duartc Mendoza, Eulogio. 17 años: 9 Campanario. Sin fecha. Oleo sobre cartón. 66 × 50.-Galicia Duarte, Benjamin 19 años: 10. Naturaleza muerta. Sin fecha. Acuarela. 34 x 22.-González Her. nándes, Juan. 17 años: 11. Crucifixión. Sin feclia. Oleo sobre cartón. 46 x 66.Hernánder Alvarez, Edmundo. 20 años: 12. Naturaleza muerta. Sin fecha. Oleo sobre tela. 47 x 63.-13. Paisaje. Sin feclı. Oleo sobre madera. $15 \times 22$ Hernández Orozco, Francisco. 20 años: 14. Chinelos. 1952. Oleo sobre tela. 50 x 65.-Lima Gonzáles, Francisco. 18 años: 15. El Gallo. 1948. Dibujo a lápiz. $50 \times$ 64.-Mendoza Blanco, Jorge. 17 años: 16. Mi maestro. Sin fecha. Acuarela. 50 x 35.-Morales Sordo, Nan. 17 años: 17. India. Escultura en mármol.-Orozco Guzmán, Artemio. 19 ã̃os: 18. Retrato. Sin fecha. Dibujo a lápiz. 48 x 37.-Ortiz Flores, María. 20 años: 19. Cabeza. Escultura en yeso.-Pérez, Alfonso Guillermo. 18 años: 20. Convento. 1952. Oleo sobre tela. 40 × 60.-Rebollo Carrillo, Luis Regino. 19 años: 21. Entrada al pueblo. Sin fecha. Oleo sobre tèla. 47 x 85.-Rodríguez Amezcua, Miguel. 21 años: 22. Estudio. Sin fecha. Dibujo a lápiz. $34 \times 24$--23. Estudio. Sin fecha. Dibujo a 
lápiz. $34 \times$ 24.--24. Estudio. Sin fecha. Dibujo a lápiz. $33 \times 23,-25$. Estudio. Sin fecha. Dibujo a lápiz. $23 \times$ 33.-26. Apunte. Sin feclia. Dibujo a tinta. $23 \times$ 33.-Salas Romero, Sergio. 20 años: 27. Retrato. Sin fecha. Temple sobre tela. 43 x 38.-Velasco León, Agustín. 19 años: 28. Desnudo. 1951. Oleo sobre tela. $51 \times 73 .-29$. Camino a Chalco. Sin fecha. Oleo sobre tela. $25 \times 31 .-V i$ suet García, Ada. 15 años: 30. Naturaleza muerta. Sin feclia. Oleo sobre cartón. $40 \times 49$.-NOTA: Todas las medidas son en centímetros.

\section{NOVIEMBRE}

* Raymond Toloczko.-Exposición de pinturas presentada por el Instituto Mexicano-Norteamericano de Relaciones Culturales en el Auditorium ubicado ct Yucatán, 63. Del 6 al 19 de noviembre.

Pinturas :

1. Toy whistles.-2. Reclineing Nude.-3. Dos locos, fiesta.-4. Woman of Celaya.-5. George's Garden.-6. Show Girls.-7. Mountain Landscape-6. Edge of town. Irapuato--9. Holy Thursday altar-10. Sunsline on the Hillside-11. Ascension.-12. Gladiolas.-13. Anniversary Cake.-14. Potted Plant.-15. Portrait of a Lady, With Fan.-16. Scorpion.-17. Activity in a River bed.-18. Landscape with Chape1.-19. Cactus.-20. Seed.-21. Girl at Window.-22. View of San Miguel.-23. Flowers, Compote Dish.-24. Woman at window.-25. Seated nude.-26. Woman Smoking.-27. Crucifixion.-28. Orange Domes, Mexican Town.-29. Bird in tree-top.-30. Portrait of Mrs. H.-31. View of Dan in Moonlight.-32. Odalesque.-33. Mexico City.-34. Madonna and Child.-35. Exotic Plants.-36. Woman Combing her hair.-37. Fruit Stall.-38. Still Life.

Dibuijos :

1. Madonna and Child.-2. Gil's Latin School.-3. The Churcl1.-4. View from ny Tower.-5. Man and two sims.-6. Lands cape-7. Factory.-8. Mrs. Rose.-o Plant Seeds.-10. Italian Gardens.-11. Mexico City Girl-Friend. Acuarcla.

* Antonio Magdalcno.-Exposición de pintura presentada por la Galería Arte Moderno, en su local de Plaza Santos Degollado, 16-C y D. Del 7 al 27 de roviembre.

1. Loma quemada.-2. Descanso.--3. Ausencia.--4. La niña de la muñeca.-5. Pan de nuertos.-6. Tejedora.-7. Valle de Texcoco.-8. Privamera en el Desierto.-9. Gigantoncs.-10. Gladiolas--11. Bandera española.-12. Ofrenda.-13. El niño de la flauta.-14. Caballito de goma.-15. Lomas de Cuernavaca.-16. Vendedor de sueños.-17. Mulata.-18. Retrato de la Srita. Josefina Procopio.-19. Máscaras,-20. Retrato del Dr. Elías Nandino.-21. Universo de [rutas.-22. Calabazas heridas. 
* José Guadalupe Ramires.-Exposición de pinturas presentada por la Sección de Artes Plásticas del Departamento de Acción Social de la Universidad de Nuevo León, en Galerías Artísticas, S. A. Desde el 7 de noviembre.

1. Peregrinos.-2. Mujeres caminando.-3. La espera.-4. La Despedida.-5. La Visita.-6. Los esposos.-7. Mujeres caminando (variación).-8. Maternidad.--9. Plañideras (tres diversos ejemplares).-10. La Danza.-11. Las Bailadoras.-12. El Andar de Lola Ochoa.-13. Mujeres tehuanas.-14. Telıuanas.-15. Mercado Juchiteco.-16. El Luto.-17. En Marcha.-18. Cruzando el río.

* Gustavo Montoya.-Exposición de pintura presentada por el Salón de la Plástica Mexicana, Galería de Ventas Libres del Instituto Nacional de Bellas Artes. Del 10 de noviembre al 10 de diciembre.

1. Niñas en el Puente. Oleo sobre tela, 1941.-2. La Niña de Rojo. Oleo sobre tela. 1949.-3. La Niña del Triciclo. Oleo sobre tela. 1949.-4. Niñas peinándose. Oleo sobre masonite. 1949.-5. La Niña del Vestido de Cuadritos Rojos. Oleo sobre tela. 1949.-6. Dos Palomas. Oleo sobre tela. 1952.-7. Gallina Ciega. Oleo sobre masonite. 1952.-8. Papalote. Oleo sobre masonite. 1952.-9. La Tolvanenera. Oleo sobre masonite. 1952.-10. La Rueda de Angeles. Oleo sobre tela. 1952.-11. La Niña de Azul. Oleo sobre tela. 1952.-I2. La Niña del Listón. Oleo sobre tela. 1952.--13. Lluvia. Oleo sobre tela. 1952.-14. Metamorfosis. Oleo sobre masonite. 1952.-15. Niñas y Mariposas. Oleo sobre masonite, 1952.-16. Pensativa. Oleo sobre tela. 1952.-17. La Niña de la Sombrilla Solfcrino. Oleo sobre masonite. 1952.

* Universidad Femenina.-Exposición de dibujos, pinturas, proyectos y maquetas de las alumnas de Decoración, presentada en el Auditoriun de la misma Universidad, sito en la Avenida Gral. Miguel Bernard, 151. Desde el 14 de noviembre.

* Bartoli--Exposición de pintura y dibujo presentada por la Galeria Prisse, L.ondres, 163. Del 14 de noviembre al 10 de diciembre.

Del 1 al 28. Dibujos blanco y negro.-Del 29 al 41. Gouaclies.-Del 42 al 55. Oleos. (Estudios).

* Instituto Nacional de Bellas Artes.-Exposición de grabados y litografías sobre Emiliano Zapata, Colección del Dr. Alvar Carrillo Gil, presentada en la Galería José Guadalupe Posada, Esquina del Dr. Vértiz y Dr. Liceaga. Desde el 17 de noviembre.

* Escuela de las Artes del Libro, Secretaría de Educación Pública.-Exposición preliminar a la prensa de los trabajos realizados por los alumnos de grabado, ediciones y encuadernación, así como por artistas profesionales en estas disciplinas que han pasado por sus aulas, presentada en la propia Escuela, desde el 19 de noviembre. 
* Thea Ramsey y Clarice Lindahl Hopps.-Exposición de pinturas, cerámica, dibujos y encuadernación, presentada por el Instituto Mexicano-Norteanericano de Relaciones Culturales, en su Auditorium, Yucatát1, 63. Desde el 21 de noviembre.

* Xavier de Oteyza.-Exposición de pintura presentada por el Ateneo Español de México, en Avenida Morelos, 26. Del 24 de noviembre al 7 de diciembre.

1. Contraluz.--2. Puerto de Motrico.-3. Calle al mediodía.-4. Ruinas.-5. Mangos y perones.-6. Interior.-7. La ria.-8. Frutas.-9. Caballito de petate--10. La copa.-11. Rosa.-12. Molino de la Mancha.-13. Peras.-14. Mesón.-15. Manzanas y botella.-16. Li1z artificial.-17. Mangos.-18. Amanecer en Ixmiquilpan.-19. Invierno en El Nuevo Baztan.-20. Estudio.-21. Llanuras de Ixtapalapa.-22. Jardín en San Angel.-23. Campana y pera.-24. Las palomas.-25. Hacienda en Tlacotepec.-26. Caza.-27. Arboles.-28. Jaime Muñoz de Baena.29. Amparo Torres de Muñoz de Baena.

* Instituto Nacional de Bellas Artes.-Exposición de la obra de profesores y alumnos de la Escuela de Pintura y Escultura de Chiapas, establecida en Tuxtla Gutiérrez, presentada en la Galería Cervantes del Museo Nacional de Artes Plásticas, esquina de Héroes y Esmeralda. Desde el 24 de noviembre.

* Ricardo Martínez.-Exposición de pinturas presentada por la Galería de Arte Mexicano, en su local de las calles de Milán, 18. Del 24 de noviembre al 30 de diciembre.

Oleos:

1. El herido.-2. Mujeres.-3. La tarde. Col. Mr. and Mrs. Robert D. Straus.-4. Mujeres con perros.-5. La casa.-6. Peones.-7. Peones.-8. Paisaje de México. Co1. Dr. Shields Warren.-9. Zapapicos.-10. Nopal.-11. Arado con paisaje.-12. Arado.-13. Tríptico.

* Jesús Guerrero Galván.-Exposición de pintura y dibujo presentada por el Instituto Nacional de Bellas Artes, en la Sala Bellas Artes del Museo Nacional de Artes Plásticas. Desde el 25 de noviembre y durante diciembre.

Pinturas :

1. Retrato de la señora Elisa Saldívar de Gutiérrez Roldán. 1941. Oleo sobre tela. $96 \times 75$. Col. Sr. Ing. Pascual Gutiérrez Roldán.-2. María Asúnsolo Niña. 1941. Oleo sobre tela. 100 × 80. Col. Sra. María Asúnsolo.-3. La Niña de la Paloma. 1942. Oleo sobre tela. 103 x 92. Col. Sra. María Asúnsolo.-4. El Parto. 1942. Vinelita sobre masonite. $76 \times 113$. Col. Galería de Arte Moderno.-5. El Banquete. 1946. Oleo sobre tela. $101 \times 126$. Col. Sr. Alfredo Ortega.-6. La mujer de los Diamantes. 1948. Oleo sobre tela. 70 x 85. Col. Sr. Dr. Josué Sáenz.-7. El Filósofo. 1948. Oleo sobre tela. 80 x 70. Col. Sr. Samuel del Vi- 
llar.-8. Los Fusilados. 1948. Oleo sobre tela. $100 \times 80$. Col. Sr. Arq. Víctor de la Lama.-9. Retrato de la señora Margarita Cejudo de Garduño. 1948. Oleo sobre tela. 130 x 110.-10. Mujer de las Peñas. 1949. Oleo sobre tela. 99 x 78. Col. Sr. Lic. José Suinaga Luján.-11. El Rap̣to. Oleo sobre tela. $150 \times 190$. Col. Sr. Dr. Josué Sáenz.-12.-San Sebastián. 1949. Oleo sobre tela. 80 x 111. Col. Sr. Lic. Manuel Moreno Sánchez.-13. Retrato de la hija del señor Manuel Harari. 1950. Oleo sobre tela. 104 x 74. Col. Sr. Manuel Harari.-14. Ia Novia del Pueblo. 1950. Oleo sobre tela. 99 x 79. Col. Sr. Lic. José Suinaga Luján.-15. Niña. 1950. Oleo sobre tela. 51 x 66. Col. Sr. Lic. José Surinaga Luján.-16. Cabeza de un Dios. 1951. Oleo sobre tela. 50 x 40. Col. Galería de Arte Moderno.-17. Doble Autorretrato. 1951. Oleo sobre tela. 54 x 69. Col. Sr. Ing. Pascual Gutiérrez Roldán.-18. Cabeza de Danzante. 1951. Oleo sobre tela. $60 \times$ 49. Col. Sr. Manuel Harari.-19. Nuestro pasado. 1951. Oleo sobre tela. 48 x 50. Col. Sr. Ing. Pascual Gutiérrez Roldán.-20. Retrato de la Sra. María de ia Luz Azuela de Macotela. 1951. Oleo sobre tela. 130 x 110. Col. Sr. Arq. Elías Macotela.-21. Retrato de la señora Columba Domínguez de Fernández. 1951. Oleo sobre tela. $205 \times$ 125. Col. Sr. Emilio Fernández.-22. Andrómeda. 1951. Oleo sobre tela. 99 × 78. Col. Galería de Arte Moderno.-23. La Tierra. Pintura mural. 1951. Vinclita sobre masonite. $174 \times 339$. Propiedad del artista.-24. Las Palomas. 1952. Vinelita sobre masonite. 73 x 58. Col. Galería de Arte Moderno.-25. Exodo. 1952. Vinelita sobre masonite. 59 x 72 . Col. Galería de Arte Moderno.-26. La Galaxia. 1952. Vinelita sobre masonite. $44 \mathrm{x}$ 59. Propiedad del artista.-27. Retrato de Carla. 1952. Oleo sobre tela. $100 \times 85$. Col. Sr. Roberto Berdecio.-28. El Fuego, 1952. Vinelita sobre masonite. $59 \mathrm{x}$ 73. Col. Galería de Arte Moderno.-29. La Protesta. 1952. Oleo sobre tela. 69 x 53. Col. Sr. Dr. Jorge Maisterrena.-30. El Llanto. 1952. - Vinelita sobre masonite. $105 \times$ 120. Propiedad del artista.-31. Mujer del Pedregal. 1952. Oleo sobre tela. $56 \times 70$. Col. Sr. Dr. Francisco Avalos García.-32. Niño cogiendo flores. 1952. Vinelita sobre masonite. 38 × 59. Col. Galería de Arte Moderno.-33. El naturalista. 1952. Vinelita sobre masonite. $38 \times 58$. Col. Galería de Arte Moderno.-34. Retrato de las Niñas Leonor y Marcela Cravioto. 1952. Oleo sobre tela. $112 \times 125$. Col. Sr. Jorge Cravioto.

\section{Dibujos :}

1. Estudio para la pintura El Rapto. 1949. Dibujo a lápiz. 69 x 39. Propiedad del artista.-2. Estudio para la pintura El Rapto. 1951. Dibujo a lápiz. 34 x 48. Propiedad del artista.-3. Proyecto para el mural La Tierra. 1952. Dibujo a lápiz. $49 \times 64$. Propiedad del artista.--4. Fstudio para el mural La Tierra. 1952. Dibujo a lápiz. $33 \times 51$. Propiedad del artista.-5. Estudio para nural. 1952. Dibujo a lápiz. $20 \times$ 27.-6. Estudio para mural. 1952. Dibujo a lápiz. $26 \mathrm{x}$ 36.-7. Estuclio para nural. 1952. Dibujo a lápiz. $25 \times 40 .-8$. Anteproyerto para el mural La Tierra. Sin fecha. Dibujo a tinta. 29 x 59. Propiedad del artista.-NOTA: Tolas las medidas son en centínetros.

* Francisco Goya y Lucientes.-Exposición de las 80 aguafuertes "Los Ca prichos", presentada por el Instituto Nacional de Bellas Artes en la Galería josé 
Clemente Orozco, del Museo Nacional de Artes Plásticas. Desde el 28 de noviembre.

* Instituto Nacional de Bellas Artes.-Exposición conmemorativa del Centenario de Leonardo de Vinci, presentada durante noviembre y diciembre, en el Palacio de Bellas Artes.

\section{DICIFMBRE:}

* Luis Abad Carretero.-Exposición de pintura titulada "Paisajes de Francia" y presentada en la Alianza Francesa, calle rle la Palıni, No. 33. Del 3 al 15 de diciembre.

1. El molino de la Galette.-2. El Calvario (Montnartre).-3. Notre-Dáme.-4. Cascada del Bosque de Bolonia.-5. La fuente de Médicis.-6. Las cuatro estaciones.-7. La plaza de la Concordia.-8. Bagatelle.-9. El parque de Sceaux.10. La avenida de Nogent.-11. Atardecer en el Marne.-12. Sena y Marne.-13. Noche en el Marne-14. Monumento a Beethoven (Vincennes).-15. El lago de Minimes (Vincennes).-16. Alto Loira.-17. Bretaña.-18. Avallón.-19. Civry (L'Yonne).-20. Pansy (L'Yonne).-21. La iglesia de Montreal.-22. Viñas (L'Islesur Serein).-23. Apunte de l'Isle-sur-Serein.-24. Apunte de Dissangy.-25. Apunte de Avallón.--26. El puerto de Orán.-27. El barranco de Raz-El-Ain.-28.-El valle de la Virgen (Miserglin).-29. Assi-Bou-Nif.-30. Místicos.-31. Los enamorados.-32. Visión de París.-33. Progreso y reacción.

* Desiderio Hernándes Xochitiatzin.-Exposición de monotipos sobre temas mexicanos, presentada por la Galeria de Arte Contemporáneo, Amberes, 12. Del 5 de diciembre al 8 de enero.

1. Miquiztli. Muerte.-2. Apanoayan. En el vado del río con el perro Techichi.-3. Tepene Monamictia. Las montañas que chocan.--4. Itatepetl. El cerro de las puntas de Obsidiana.-5. Cehuecayan. En los collados donde hiela.-6. Itzehecayan. Donde el viento es de Obsidiana.-7. Teocelohualoyan. El tigre que se come al corazón.-8. Apanhuiayo. En el agua negra con la lagartija Xochitonal.-9. Chiconauhapan. En las nuevas corrientes.-10. Mictlan. Donde mueren los muertos.-11. Teoyahuitl. El dador azul.-12. Tlaloc-Teopixccelotl Tlapaltlahcuilohc. Dios de la Lluvia-Sacerdote. Tigre-Pintor,-13. Nopalli. Nopales.-14. Ehecatl. Viento Advocación de Quetzalcoatl.-15. Tlaloc. Dios de la Lluvia.-16. Macuilxochitl. Deidad de las Flores,-17. Cemihcacoatl. Serpiente de la Eternidad-18. Quetzalcoatl. Deidnd Cultura.-19. Miquiztlxochicuepone. Muerte Florida.-20. Tochtli. Conejo.-21. Coatl. Serpiente-22. Techichi. Perrito Funerario.-23. Ocelotl. El Tigre.-24. Payaso.

* Galería de Arte Contemporáneo.-Exposición venta de fin de año, de pinturas, grabados, esculturas y fotografías, presentada en su local de Amberes, 12. Del 5 de diciembre al 8 de enero. 
Expositores :

Ignacio Aguirre, Lola Alvares Bravo, Raúl Anguiano, Robin Bond, Arenas Betancourt, Fedcrico Cantú, Castro Pacheco, Lconora Carrington, Joaquín Clausell, Salvador Conde, Raúl Conde, Pedro Coronel, Francisco Dosamantes, Jesís Guerero Galván, María Izquierdo, Carlos Mérida, Guillermo Meza, Roberto Montenegro, José Clemente Orozco, Trinidad Osorio, Pablo O'Higgins, Feliciano Peña, Emma Reyes, Chucho Reyes, José Reyes Meza, Iuan Soriano, Rufino Tamayo, Taller Gráfico Popular, Francisco Zúñiga.

* Galería "Arte Moderno".-Exposición remate, por cambio de local, de grabados, dibujos, acuarelas, gouaches, óleos, vinelitas y terracotas, de la Escuela Mexicana Contemporánea y Pintores y Grabadores de la Escuela de París, presentada ell su local de Plaza Santos Degollado, 16-C y D. Del 5 al 31 de diciembre.

* J. Cañas.-Exposición de animales hechos en España, Inglaterra, Norteamérica y México, presentada en la Galería de Arte de la Librería Juárez, 102. Del 9 de diciembre al 9 de enero.

* Antonio Rodríguez Luna-Exposición de pintura presentada por Decor, S. A., en Pasco de la Reforma, 121. Del 10 al 31 de diciembre.

1.-Exodo.-2. La planchadora.-3. Vendedora.-4. La modelo.-5. Albergue de noche.-6. Manicomio.-7. En1 el camión.-8. Los cazadores.-9. Desnudo en el taller.-10. Interior con figura.-11. El taller.-12. Naturaleza muerta.-13. Lago de Chapulteuec.-14. Bosque de Chapultepec.-15. Montañas.-16. Retrato de mi mujer.-17. Mujer planchando.-18. Mesa de trabajo.-19. Mesa de pintor.-20. Mendiga.-21. Exilio.-22. Retrato de María Agueda Méndez.-23. Retrato de Fernando Bergamín.-24. Retrato.-25. Naturaleza muerta.

* Patronato Nacional de las Artes e Industrias Populares.-Exposición titulada "Posadas, Navidad y Reyes", presentada en el Museo Nacional de Artes e I11dustrias Populares, Av. Juárez, 44. Desde el 10 de diciembre.

* Vlady.-Exposición de pintura y dibujo, presentada por la Galería Prisse, Londres, 163. Del 11 de diciembre al 10 de eneto.

Oleos :

1. San Sebastián,--2. Sebastián y el Emperador,-3. San Sebastián.-4. La Condena. -5. Grabado del siglo xv.-6. Plaza de la Saussicre, París.-7. Fragmento del Héroe.-8. Centauro.-9. El beso.-10. París.-11. Casa Parisina--12. E1 Verdugo.-13. Cabeza de Boyardo Jove11.-14. El jarocho.-15. Planta.-16. Retrato de la Sra. A. Elizondo.-17. Retrato de Marta Ros.-18. J. C. Orozco.19. Desnudo. 
Dibujos:

1, 2, 3, 4, 5, 6. Estudios de San Sebastián.-7. París. Acuarela.-8. Versallesca. Acuarela.-9. El Centauro.-10. Desnudo.-11. Paisaje de Lluvia.-12. Montserrat.-13. Andalucía.-14. Provenza. Gouache. Hojas.-15. El Puritano holandés.-16. Hojas secas.-17. El Jaripeo.-18. Tepoztlán.-19. Personajes mexicanos.-20. París.-21. Percherón.-22. Mar.-23. Bailarina.-24. Andalucía. 25. La Pedrera.-26. Retrato de Bartoli.--27. Retrato de Ondalecio Prieto.-28. Retrato de Goytia.-29. Retrato de la señora Bayo.-30. Retrato de la señora Bosch.-31. Retrato de la señora Kawage.

* Instituto Nacional de Bellas Artes.-Exposición de arte mexicano, estan1pas, óleos, temples, dibujos, acuarelas y gouaclies, presentada con fines comerciales con motivo de la Navidad, en el Salón de la Plástica Mexicana, Galería de Ventas Libres. Del 15 de dicienubre al 6 de enero.

Expositores :

Ignacio Aguirre, David Alfaro Siqueiros, Raúl Anguiano, Dr. Atl, Abelardo Avila, Alberto Beltrán, Angel Bracho, Celia Calderón, Federico Canti, Fernando Castro Pacheco, Josć Cháves Morado, Olga Costa, Dolores Cucto, Germán Cueto, Gonzalo de la Paz Pérez, Francisco Dosamantes, Jesúr Escobedo, Iosé García Narezo, Jorge González Camarcna, Manuel Gonsález Serrano, Jesús Guerrero Galván, Xavier Guerrero, Maria Isquierdo, Frida Kahlo, Amador Lugo, Ricardo Martínez, Leopoldo Méndez, Carlos Mérida, Guillermo Meza, Gustavo Montoya, Francisco Mora, Nicolás Moreno, Luis Nishizarva, Juan O'Gorman, Pablo O'Higgins, Carlos Orozco Romero, Feliciano Peña, Fanny Rabel, Iosi' Reyes Meza, Carlos Sánchcz, Juan Soriano, Rufino Tamayo, Cordelia Urueta, Héctor Xavier, Desiderio H. Xochitiotzin, Alfredo Zalce.

* Gral. Ignacio M. Beteta.-Exposición de acuarelas, presentada en la Sala de Exposición del Hotel del Prado, por los señores licenciados Carlos Novoa, Raúl Noriega y señor Carlos Trouyet. Desde el 17 de diciembre. El producto de la venta de las obras expuestas, será destinado a cstablecer becas para estudiantes de pintura.

Acuarelas :

1. Calle en Tierra Caliente-2. Calle de Guanajuato.-3. Calle de Pacluuca.-4. Balcón sobre el paisaje.-5. Calle de Anecameca.-6. Las Casitas y el Cerro de la Silla.-7. Barrio de Monterrey.-8. Portón de los Morales.-9. Calle de Regina. -10. Plaza de Orizaba.-11. La Iglesia del Pueblo.-12. Alhóndiga de Granaditas.-13. Bahía de Acapulco.-13-bis. Pórtico de San Jacinto.-14. San Miguel Allende.-14-bis. Calle de San Angel.-15. Montmartre.-16. La Maisson Rouge.17. Una calle de Montmartre.-18. Doville.-19. Palacio en Génova.- 20. San Daniello.-21. Puerta de Asís.-22. Perugía.-23. Calle de Perugía.-24. Calle de Nápoles.-25. Sorrento.-26. Callejón Florentino.-27. Columnas del Foro, Ro- 
ma.-28. Ruinas Romanas.-29. Calle en Toledo.-30. Callejón en Toledo.-31. Viejo Madrid.-32. Callejón en Viejo Madrid.-33. Helsinki.-34. El Puerto de Helsinki.--35. Estocolmo.--36. Puerto de Pescadores.-37. Perspectiva del Hejsinki.-38. Pueblo Texano.-39. Calle de Washington, D. C.-40. Avenida en el Parque Washington.-41. Haití.-42. (?).-43. Parque en Otoño. Washington.

* Francisco González.-Exposición de pinturas, grabados, cerámicas y esculturas, presentada en la calle de París $N^{0} 74$ de Coyoacán, D. F., del 19 al 31 de diciembre. 
DOI: http://dx.doi.org/10.22201/iie.18703062e.1953.sup1.2455 